\title{
LSD1-mediated enhancer silencing enables endocrine cell development through attenuation of retinoic acid signalling
}

\author{
Nicholas K. Vinckier ${ }^{1,7}$, Nisha A. Patel ${ }^{1,7}$, Allen Wang ${ }^{1}$, Jinzhao Wang ${ }^{1}$, Hung-Ping Shih ${ }^{1,5}$, \\ Jianxun Wang ${ }^{2}$, Ulupi S. Jhala ${ }^{3}$, Michael G. Rosenfeld ${ }^{2}$, Christopher W. Benner ${ }^{4}$, Maike \\ Sander ${ }^{1, *}$ \\ ${ }^{1}$ Departments of Pediatrics and Cellular \& Molecular Medicine, Pediatric Diabetes Research \\ Center, Sanford Consortium for Regenerative Medicine \\ ${ }^{2}$ Howard Hughes Medical Institute and Department of Medicine \\ ${ }^{3}$ Department of Pediatrics and Pediatric Diabetes Research Center \\ ${ }^{4}$ Department of Cellular \& Molecular Medicine \\ University of California, San Diego, La Jolla, CA 92093, USA \\ ${ }^{5}$ present address: Department of Translational Research \& Cellular Therapeutics, Diabetes \& \\ Metabolism Research Institute, City of Hope, Duarte, CA91010 \\ ${ }^{7}$ These authors contributed equally \\ "Correspondence: masander@ucsd.edu
}




\section{Abstract}

Developmental progression depends on temporally defined changes in gene expression mediated by transient exposure of lineage intermediates to signals in the progenitor niche. To identify a possible contribution of cell-intrinsic epigenetic mechanisms to signal-induced transcriptional responses, we manipulated the signalling environment and activity of the histone demethylase LSD1 during stepwise differentiation of gut tube intermediates into pancreatic endocrine cells. Analysis of enhancer and transcriptome landscapes revealed that lineage progression and endocrine cell differentiation requires LSD1-mediated silencing of transiently active retinoic acid (RA)-induced enhancers. In the absence of LSD1, early RA-responsive enhancers remain partially active despite RA removal, resulting in perduring expression of RAinduced genes, and failure to progress in development. Our findings identify LSD1-mediated enhancer silencing as a cell-intrinsic epigenetic feedback mechanism by which the duration of the transcriptional response to a developmental signal is limited. Given LSD1's requirement in numerous developmental contexts, the here-described mechanism would be broadly relevant. 


\section{Introduction}

During development, intermediate progenitors progress toward a distinct cell fate as a result of sequential instructions by signalling cues in the progenitor niche. The duration of a developmental signal has to be limited in order for developmental intermediates to appropriately respond to the next inductive cue. For example, pancreas induction from the foregut endoderm requires retinoic acid (RA) signalling, but thereafter RA signalling activity needs to be dampened for pancreatic progenitors to correctly interpret pro-endocrine differentiation cues ${ }^{1}$. Thus, signalling cues are interpreted in a highly context-dependent manner and signals need to be temporally limited to delineate critical competence windows for developmental transitions. An open question is whether removal of the signal is sufficient to terminate a response to a signal or whether cell-intrinsic mechanisms at the level of the responder tissue enable developmental transitions by limiting the duration of signal-induced transcriptional responses.

Spatiotemporal gene expression during development is regulated by transcriptional enhancers ${ }^{2}$. Chromatin state at enhancers is a significant determinant of transcriptional responsiveness to environmental signals, and enhancers respond to signalling cues by modifying their chromatin state. Enhancers can exhibit an inactive, poised, or active chromatin state. Inactive enhancers are characterised by compact chromatin and absence of active histone modifications, whereas poised enhancers are nucleosome-free and marked by mono- and dimethylation of histone $\mathrm{H} 3$ at lysine $4(\mathrm{H} 3 \mathrm{~K} 4 \mathrm{me} 1 \text { and } \mathrm{H} 3 \mathrm{~K} 4 \mathrm{me} 2)^{3-5}$. The transition from an inactive to a poised enhancer state during development coincides with a gain in cellular competence of lineage intermediates to respond to inductive signalling cues ${ }^{5}$. Thus, developmental competence can be defined as a temporal state during which the epigenetic landscape is permissive for responding to environmental signals. Signal-dependent transcription factors (TFs) activate poised enhancers by recruiting co-activator complexes containing histone acetyltransferases (HATs) that deposit H3K27 acetylation (H3K27ac) marks, thereby transforming the poised enhancer into one 
that actively supports transcription ${ }^{6}$. It is unknown whether or not the erasure of these epigenetic marks is a prerequisite for termination of one competence window and transition to the next.

Lysine-specific demethylase 1 (LSD1), also known as KDM1A, regulates chromatin by catalysing the removal of mono- and di-methyl marks from $\mathrm{K} 4$ at histone $\mathrm{H} 3{ }^{7}$, thus rendering poised enhancer chromatin inactive ${ }^{8}$. This process has been called enhancer decommissioning and is coupled to complete silencing of associated genes ${ }^{8}$. Despite its role in enhancer silencing, LSD1 frequently resides in complexes of active enhancers ${ }^{9-11}$. In the context of acetylated histones, LSD1 activity and demethylation of H3K4 is inhibited ${ }^{9}$. Therefore, current evidence suggests that histones need to be deacetylated before LSD1 can decommission active enhancers. Consistent with this mechanism, LSD1 occupies enhancers of pluripotency genes in pluripotent stem cells and decommissions these enhancers only when pluripotent stem cells undergo differentiation ${ }^{8}$. Whether LSD1-mediated regulation of enhancer chromatin plays a role in defining developmental competence windows and enabling sequential cell state transitions remains unknown.

Here, we asked whether epigenetic mechanisms can limit the duration of an inductive signal throughout a developmental time course, thereby defining distinct competence windows and preventing inappropriate responses to developmental signals. To investigate this, we manipulated LSD1 activity and RA signalling in a human embryonic stem cell (hESC)-based differentiation system, where cells progress stepwise in defined conditions toward the pancreatic endocrine cell fate. We show that LSD1-mediated enhancer decommissioning limits the time window, during which cells remain responsive to RA and express RA-induced genes. When LSD1 activity is inhibited immediately after pancreas induction, RA-induced genes fail to be silenced despite removal of RA as an inductive signal, rendering cells unable to undergo endocrine cell differentiation. Thus, our results show that loss of LSD1 function critically alters the epigenetic landscape that terminates the competence window for RA signalling, resulting in subsequent failure of developmental intermediates to differentiate. These findings identify modification of the 
bioRxiv preprint doi: https://doi.org/10.1101/716647; this version posted August 1, 2019. The copyright holder for this preprint (which was not certified by peer review) is the author/funder. All rights reserved. No reuse allowed without permission.

epigenome as an important cell-intrinsic mechanism for sharpening transcriptional responses to developmental signals. 


\section{Results}

\section{Human Endocrine Cell Development Requires LSD1 Activity During a Narrow Time Window}

\section{Early in Pancreas Development}

To investigate possible roles for LSD1 during defined windows of transition to a differentiated cell type, we employed a hESC differentiation system, in which cells progress stepwise toward the pancreatic endocrine cell lineage through sequential exposure to signalling cues that guide corresponding cell state transitions in the developing embryo (Fig. 1a) ${ }^{5,12-14}$. In this differentiation system, LSD1 was broadly expressed throughout progression to the endocrine cell stage (EN) (Supplementary Fig. 1a,b). We verified LSD1 expression in pancreatic progenitor cells and differentiated endocrine cells in human foetal and adult tissue (Supplementary Fig. 1c).

To assess whether LSD1 is required for pancreatic development, we started by blocking LSD1 activity immediately after the initiation of pancreas induction during the transition from the early (PP1) to the late (PP2) pancreatic progenitor cell stage (LSD1i ${ }^{\text {early }}$ ), using the irreversible LSD1 inhibitor tranylcypromine (TCP) (Fig. 1a). PP1 and PP2 progenitors are distinguished by increasing expression of pancreatic TFs that commit progenitors to the endocrine cell fate, including PDX1 and NKX6.1 ${ }^{12}$. Thus, PP1 cells represent a less committed pancreatic progenitor, whereas PP2 cells exhibit features of endocrine cell commitment. LSD1 inhibition during the PP1 to PP2 transition did not affect expression of PDX1 or NKX6.1 (Supplementary Fig. 1d,e), indicating that endocrine-committed pancreatic progenitors can form in the absence of LSD1. However, when LSD $1 i^{\text {early }}$ cells were further differentiated to the EN stage, we observed a striking absence of endocrine cells at the EN stage, while progenitor cell markers remained largely unaffected (Fig. 1b-d). The same phenotype was observed when culturing in the presence of several other irreversible and reversible LSD1 inhibitors during the PP1 to PP2 transition (Supplementary Fig. 2a). The normal progression through endocrine commitment but absence of endocrine cells after LSD1 inhibition indicated a specific requirement for LSD1 activity during 
endocrine cell differentiation. To directly test whether the endocrine cell differentiation step requires LSD1 activity, we added TCP or the LSD1 inhibitor GSK2879552 during the PP2 to EN transition (LSD1i ${ }^{\text {late }}$ ) (Fig. 1a). Surprisingly, this later inhibition of LSD1 did not perturb endocrine cell formation (Fig. 1b-d and Supplementary Fig. 2b-d). Thus, endocrine cell development requires LSD1 activity during a narrow time window after pancreas induction, but not during endocrine cell differentiation. This indicates that LSD1-mediated changes during the PP1 to PP2 transition affect the ability of developmental precursors to undergo endocrine differentiation later in development.

\section{LSD1 Inhibition Prevents Enhancer Silencing}

Given LSD1's role as a chromatin modifier ${ }^{7}$, we investigated whether loss of LSD1 activity during the PP1 to PP2 transition could block endocrine cell development due to aberrant regulation of the epigenome. To this end, we performed chromatin immunoprecipitation sequencing (ChIP-seq) for LSD1 at the PP1 stage and mapped chromatin state changes at LSD1-bound sites during the PP1 to PP2 transition without and with LSD1 inhibition. We identified a total of 15,084 LSD1 peaks throughout the genome (Supplementary Fig. 3a and Supplementary Table 1). Of these, the vast majority were promoter-distal (11,799; > 3kb from TSS; Supplementary Fig. 3a and Supplementary Table 1), which is consistent with prior observations in hESCs ${ }^{8}$.

Distal enhancers are highly dynamic during pancreatic development ${ }^{5}$, leading us to postulate that LSD1 controls endocrine cell differentiation by regulating changes in enhancer chromatin state during the PP1 to PP2 transition. To test this, we performed ChIP-seq for the active enhancer mark H3K27ac ${ }^{4,15,16}$ at the PP1 and PP2 stage. Reasoning that effects of LSD1 on the active enhancer landscape would be most likely to affect gene expression and therefore have high propensity to be causal for the phenotype, we isolated enhancers that are active at PP1 and/or PP2 and also bound by LSD1 at the PP1 stage. This analysis revealed three groups of LSD1-bound enhancers: Group $1(\mathrm{G} 1)$ enhancers $(n=1345)$ underwent deactivation during 
the PP1 to PP2 transition ( $\geq 2$-fold decrease in H3K27ac); Group 2 (G2) enhancers ( $n=765$ ) were active at both PP1 and PP2 (< 2-fold change in H3K27ac); and Group 3 (G3) (n = 511) enhancers underwent activation ( $\geq 2$-fold increase in H3K27ac) during the PP1 to PP2 transition (Fig. 2a and Supplementary Table 2a-c). We next examined the "poised" chromatin modifications $\mathrm{H} 3 \mathrm{~K} 4 \mathrm{me} 1$ and $\mathrm{H} 3 \mathrm{~K} 4 \mathrm{me} 2$ at these three enhancer groups during the PP1 to PP2 transition. We observed that LSD1-bound G1 enhancers exhibited a marked decrease in H3K4me1 and H3K4me2 (Fig. 2b), consistent with known roles of LSD1 as a H3K4me2 and H3K4me1 demethylase ${ }^{7,17}$. Thus, G1 enhancers are decommissioned during the PP1 to PP2 transition. To investigate whether LSD1 recruitment is regulated at these decommissioned enhancers, we examined LSD1 occupancy in PP2 cells. We observed a decrease in LSD1 ChIP. seq signal in the decommissioned G1 enhancer group from PP1 to PP2, but not in the G2 and G3 enhancer groups (Fig. 2c). Since endocrine cell development requires LSD1 activity during the PP1 to PP2, but not the PP2 to EN transition, the transient recruitment of LSD1 to G1 enhancers only at the PP1 stage could signify a specific importance of this enhancer group for the endocrine differentiation phenotype.

To determine whether LSD1 activity is required for remodelling enhancer chromatin during the PP1 to PP2 transition, we analysed H3K27ac, H3K4me2, and H3K4me1 modifications in PP2 cells after LSD1 inhibition (LSD1 $\mathrm{i}^{\text {early }}$ ). In all three enhancer clusters, we observed little effect of LSD1 inhibition on H3K27ac dynamics during the PP1 to PP2 transition (Fig. 2d,e and Supplementary Fig. 3b). The activation (i.e. acetylation) of G1 enhancers coincided with the pancreas induction step from gut tube (GT) to PP1 (Fig. 2d,e and Supplementary Fig 3c). Confirming our prior observation that pancreas-specific enhancers are poised prior to activation ${ }^{5}, \mathrm{G} 1$ enhancers exhibited significant deposition of H3K4me1 at the GT stage (Fig. 2d). Thus, G1 enhancers become activated during pancreas induction and are quickly inactivated as pancreatic endocrine development proceeds. Consistent with LSD1's enzymatic activity, LSD1 inhibition during the PP1 to PP2 transition led to significant accumulation of H3K4me1 and H3K4me2, 
particularly at G1 enhancers (Fig. 2d,e and Supplementary Fig 3c ; p < 2.2e-16, Wilcoxon ranksum test). H3K4me1 and H3K4me2 levels at G1 enhancers in LSD1 ${ }^{\text {early }}$ PP2 cells were similar to levels at PP1, showing a requirement for LSD1 in decommissioning these enhancers during the PP1 to PP2 transition. Although H3K4me1 and H3K4me2 levels were also increased at G2 and G3 enhancers after LSD1 inhibition, the effect was less pronounced compared to G1 enhancers (Supplementary Fig. 3b). Importantly, H3K4me1 and H3K4me2 deposition was not increased at enhancers not bound by LSD1 (Supplementary Fig. 3d and Supplementary Table 2d), demonstrating specificity of the effect to LSD1-bound enhancers. Combined, this analysis identified a LSD1-regulated set of enhancers that is activated upon addition of pancreas-inductive factors during the GT to PP1 transition and deactivated (i.e. deacetylated) and decommissioned (i.e. demethylated) when these factors are withdrawn from PP1 to PP2 (Fig. 2f). We find that deacetylation of these enhancers occurs largely independent of LSD1, but that LSD1 is required for enhancer decommissioning and thus complete enhancer silencing. Given prior findings that LSD1 activity is inhibited in context of acetylated histones ${ }^{9}$, these results suggest that histone acetylation from GT to PP1 prevents LSD1-mediated enhancer silencing and that LSD1independent H3K27ac removal allows LSD1 to silence these enhancers during the PP1 to PP2 transition.

\section{LSD1 Represses Transiently Expressed, Retinoic Acid-Dependent Genes}

We next sought to investigate possible effects of the observed chromatin changes on gene expression and compared RNA-seq profiles of control PP2 cells and PP2 cells after LSD1 inhibition (LSD1iearly). This analysis identified 445 genes that decreased and 955 genes that increased in expression due to LSD1 inhibition (Fig. 3a and Supplementary Table 3; $p<0.05, \geq$ 1.5-fold change). To identify those genes most likely directly regulated by LSD1, we performed enrichment analysis for G1, G2, and G3 enhancers as well as other distal LSD1 binding sites near genes up- and down-regulated after LSD1 inhibition (TSS \pm 100 kb from LSD1 peak). G1, G2, 
and G3 enhancers, but not other distal LSD1 binding sites, showed significant enrichment close to genes up-regulated due to LSD1 inhibition (Fig. 3b and Supplementary Table 2). The majority of the enhancer-associated up-regulated genes were near G1 enhancers (Fig. 3c). By contrast, we observed significant depletion or lack of enrichment of distal LSD1-bound sites near genes down-regulated in LSD1 $1{ }^{\text {early }}$ cells (Supplementary Fig. 4a). Together, this analysis suggests that direct LSD1 target genes are overrepresented among genes up-regulated after LSD1 inhibition, whereas down-regulated genes are not directly LSD1-regulated.

We next determined how candidate G1, G2, and G3 enhancer target genes (Supplementary Table 4) are regulated over the developmental time course (Fig. $\mathbf{3 d}$ and Supplementary Fig. 4b,c). G1 enhancer-associated genes that were up-regulated by LSD1 inhibition were induced during the GT to PP1 transition and then down-regulated during the transition to PP2 (Fig. 3d). Thus, the expression pattern of G1 enhancer-associated, LSD1regulated genes mirrors the activity pattern of G1 enhancers, which are inactive at the GT stage, active at the PP1 stage, and LSD1-dependently decommissioned during the PP1 to PP2 transition (Fig. 2d). Unbiased analysis of over-represented pathways among genes up-regulated by LSD1 inhibition revealed enrichment for genes linked to RA signalling in the $G 1$, but not $G 2$ or $G 3$, enhancer-associated group of genes, suggesting an important role for RA signalling in the regulation of G1 enhancer-associated genes (Fig. 3e, Supplementary Fig. 4b,c and Supplementary Table 5). To simulate the requirement for RA signalling in pancreatic lineage induction in vivo ${ }^{18,19}, \mathrm{RA}$ is one of three growth factors added to the culture medium during the GT to PP1 transition to induce pancreatic genes (Fig. 1a) ${ }^{12}$. RA is subsequently withdrawn during the transition from PP1 to PP2. Thus, the activity of G1 enhancers and expression of associated genes precisely coincides with the addition and removal of RA.

\section{Prolonged Exposure of Pancreatic Progenitors to RA Phenocopies LSD1 Inhibition}


$\mathrm{RA}$ regulates gene expression by binding to its heterodimeric receptor composed of retinoic acid receptor $(R A R)$ and retinoid $X$ receptor $(R X R)^{20}$. In the absence of $R A$, the $R A R / R X R$ heterodimer recruits co-repressors leading to histone deacetylation and gene silencing, while RA binding to RAR/RXR induces recruitment of HATs, mediating histone acetylation and activation of RAdependent genes. Hence, the observed pattern of H3K27 acetylation at G1 enhancers during progression from GT to PP2 (Fig. 2d) is consistent with RA-dependent regulation of these enhancers. To determine whether G1 enhancers are indeed regulated by RA, we performed TF binding motif enrichment analysis. This analysis revealed significant enrichment of the motif for the RAR/RXR heterodimer at G1 compared to $\mathrm{G} 2$ and $\mathrm{G} 3$ enhancers (Fig. 4a and Supplementary Table 6). ChIP-seq analysis for RXR, which is the obligatory binding partner for all RAR isoforms, confirmed RXR binding (Fig. 4b), thus indicating RA-dependent regulation of G1 enhancers.

To determine whether failure to silence RA-induced genes could be the mechanism by which LSD1 inhibition blocks endocrine cell differentiation, we tested whether extended RA exposure of pancreatic progenitors abrogates endocrine cell differentiation in a similar manner as LSD1 inhibition. To extend the time period of RA signaling, we added the RA analog TTNPB not only from the GT to PP1 stage, but also during the PP1 to PP2 transition (Fig. 4c, RA ${ }^{\text {extended }}$ ) and then differentiated RA ${ }^{\text {extended }}$ cultures to the EN stage. Mimicking the LSD1i ${ }^{\text {early }}$ phenotype, EN stage $\mathrm{RA}^{\text {extended }}$ cultures exhibited a striking absence of endocrine cells, while progenitor cell markers were unaffected (Fig. 4d,e and Supplementary Fig. 5a,b). Thus, RA exposure of pancreatic progenitors has to be transient for endocrine cell differentiation to occur.

We next employed RNA-seq analysis to identify genes dysregulated as a result of prolonged RA exposure. Only 96 genes were down-regulated and 69 up-regulated in RA ${ }^{\text {extended }}$ PP2 cultures (Fig. $4 f$ and Supplementary Table 7; $p<0.05, \geq 1.5$-fold change), suggesting that the endocrine differentiation block is mediated by dysregulation of a modest number of genes. Strikingly, genes up-regulated after LSD1 inhibition were significantly enriched among the genes 
also increased in expression after prolonged RA exposure (Fig. 4f), and genes near G1 enhancers largely accounted for this enrichment (Fig. 4g). Among the genes up-regulated by both LSD1 inhibition and prolonged RA exposure were numerous genes known to be regulated by RA, including genes encoding HOX TFs and RA-inactivating enzymes of the CYP26 family (Fig. 4h), supporting the notion that RA-induced genes need to be silenced for cells to acquire competence for endocrine cell differentiation. Together, our findings support a model whereby LSD1 silences RA-regulated genes by decommissioning their enhancers upon RA withdrawal, thereby ensuring transient, ligand-dependent expression of RA-induced genes. Under conditions of prolonged RA exposure, RA-mediated recruitment of HATs maintains histone acetylation ${ }^{20}$, which inhibits LSD1 activity ${ }^{9}$ and prevents enhancer decommissioning during the PP1 to PP2 transition.

\section{LSD1 Dampens Future Responses to RA}

We sought to further substantiate that LSD1 regulates RA responsiveness and that the block in endocrine cell differentiation after LSD1 inhibition is linked to aberrant expression of RAdependent genes. We predicted that endocrine cell differentiation should not be perturbed when cells are re-exposed to RA during the PP2 to EN transition, because enhancers of early RAresponsive genes are already decommissioned at the PP2 stage (Fig. 2d,e and Supplementary Fig. 3d). To test this, we re-introduced RA into the culture medium during the PP2 to EN transition (RA ${ }^{\text {late }} ;$ Fig. 5a). As hypothesised, and in stark contrast to RA ${ }^{\text {extended }}$ cultures (Fig. 4d,e), endocrine cells were present in $\mathrm{RA}^{\text {late }} \mathrm{EN}$ stage cultures in numbers almost identical to control cultures (Fig. 5b,c and Supplementary Fig 6a,b). Thus, similar to addition of the LSD1 inhibitor (Fig. 1a-d), addition of RA prevents endocrine cell formation only during the PP1 to PP2 but not the PP2 to EN transition.

To further test whether enhancer decommissioning is a mechanism by which to regulate RA responsiveness, we re-exposed cells to RA from PP2 to EN (RA late) with or without prior LSD1 inhibition during the PP1 to PP2 transition (Fig. 5a). As expected, LSD1i ${ }^{\text {early }}+\mathrm{RA}^{\text {late }}$ treatment 
completely blocked endocrine cell differentiation, phenocopying LSD1i ${ }^{\text {early }}$ cultures (Supplementary Fig. 6c,d). To determine whether prior LSD1 inhibition alters the extent to which RA-regulated genes can be induced by RA, we measured gene expression changes in response to RA. To this end, we compared gene expression at the EN stage in LSD1i ${ }^{\text {early }}$ vs. LSD $1 \mathrm{i}^{\text {early }}+$ $\mathrm{RA}^{\text {late }}$ and control vs. RA ${ }^{\text {late }}$ conditions (Fig. 5d and Supplementary Table 8). We used LSD1i $\mathrm{i}^{\text {early }}$ EN cells, rather than control EN stage cultures, as a reference for the cells re-exposed to RA after LSD1 $1{ }^{\text {early }}$ treatment to control for the population bias caused by the lack of endocrine cells after LSD1 inhibition. Strikingly, most genes near G1 enhancers that are up-regulated by both LSD1 inhibition (Fig. 3a) and extended RA exposure (Fig. 4f), including HOXA1, HOXA3, HOXC4, and CYP26B1, exhibited a higher degree of inducibility by RA with prior LSD1 inhibition. Thus, LSD1 dampens future RA responsiveness in cells that have been previously exposed to RA. We observed no difference in the expression of LSD1, RARs, or RXRs between the different conditions (Supplementary Fig. 6e), indicating that alteration of the epigenetic state rather than differences in TF and co-factor expression explain the heightened RA responsiveness after LSD1 inhibition.

\section{Lsd1 Has a Specific Role in Development of the Endocrine Cell Lineage In Vivo}

To verify our in vitro findings in an in vivo model, we deleted $L s d 1$ conditionally in mice to determine whether endocrine cell differentiation requires Lsd1 activity transiently in early pancreas development, as observed in the hESC differentiation system. As in the human pancreas (Supplementary Fig. 1c), Lsd1 was highly expressed in pancreatic progenitors and endocrine cells (Supplementary Figs. 7a,b). To selectively inactivate $L s d 1$ in early pancreatic progenitors similar to LSD1 inhibition at PP1, we generated $P d x 1 C r e ; L s d 1^{\text {flox/flox }}\left(L s d 1^{\Delta \text { pan }}\right)$ mice (Fig. 6a). In $L s d 1^{\Delta \text { pan }}$ embryos, key aspects of early pancreatic development, such as the induction of early pancreatic markers and outgrowth of the tissue buds, were unperturbed (Fig. $\mathbf{6 b}, \mathbf{c}$ and Supplementary Fig. 7c). Furthermore, the expression of exocrine cell markers, as well as rates 
of cell proliferation and cell death were not affected by Lsd1 deletion (Supplementary Fig. 7c,d). However, by embryonic day (e) 15.5, when widespread endocrine cell differentiation is evident in control mice, $L s d 1^{\Delta \text { pan }}$ embryos exhibited an almost complete lack of endocrine cells (Fig. 6b), a phenotype that remained apparent at postnatal day (P) 0 (Fig. 6b,d). Thus, as in the hESC differentiation system, Lsd1 inactivation in early pancreatic progenitors of mice prevents endocrine cell formation. In vivo inactivation of $L s d 1$ further revealed that Lsd1 activity is selectively required for development of the endocrine lineage, while being dispensable for exocrine cell formation and key aspects of early pancreatic development, such as maintenance of pancreatic progenitors and growth of the developing organ.

To determine when precisely Lsd1 is required for endocrine cell development, we crossed $L s d 1^{\text {flox/flox }}$ and $P d x 1 C r e E R^{T M}$ mice, allowing for temporally controlled Lsd1 inactivation in pancreatic progenitors by tamoxifen administration (Fig. 6e). Consistent with the phenotype of $L s d 1^{\Delta \mathrm{pan}}$ mice, tamoxifen administration at e10.5 ( $L s d 1^{\Delta \text { early }}$ mice) resulted in almost complete absence of endocrine cells (Fig. 6f). Remaining endocrine cells in $L s d 1^{\Delta \text { early }}$ mice were mostly Lsd1 ${ }^{+}$due to mosaic deletion (Supplementary Fig. 7e). By contrast, tamoxifen injection at e12.5 (Lsd1 ${ }^{\Delta l a t e}$ mice), which targets late pancreatic progenitors shortly before endocrine cell differentiation similar to PP2 cells, did not affect endocrine cell formation, as evidenced by the presence of Lsd1-deficient hormone ${ }^{+}$cell clusters (Fig. 6f and Supplementary Fig. 7e). Therefore, as in the hESC differentiation system, endocrine cell differentiation in mice requires Lsd1 activity during a narrow time window in early pancreas development. Combined, our in vitro and in vivo findings support a model whereby LSD1 controls progression to the endocrine cell stage by limiting the duration of early RA signaling through chromatin modification at RAresponsive enhancers. 


\section{Conclusions}

Proper formation of terminally differentiated cell types requires precise timing, amplitude, and, as illustrated by this study, duration of developmental signals. Our findings show that decommissioning (i.e. complete inactivation) of RA-dependent early pancreatic enhancers temporally limits the expression of RA-induced genes after RA is removed, thereby creating a sharp and transient gene expression response to RA. This mechanism can explain how the duration of a transcriptional response to a transient inductive signal is limited during a developmental time course. Furthermore, we observed that enhancer decommissioning dampens future gene inducibility by the same signal. Our findings suggest that developmental competence windows are terminated through erasure of epigenetic marks, providing a mechanistic understanding of why developmental signals evoke context-dependent cellular responses. Underscoring the importance of enhancer silencing for developmental progression, we find that the inability to decommission RA-dependent enhancers and down-regulate RA-induced genes coincides with subsequent failure to initiate endocrine cell differentiation. We propose that LSD1mediated enhancer decommissioning is a responder tissue-intrinsic mechanism by which perduring transcriptional effects of transient developmental signals are prevented. By helping close competence windows during rapid developmental transitions, this mechanism creates a conducive state for correct interpretation of the next inductive signal.

\section{Mechanisms of Pancreatic Lineage Progression}

Our findings indicate that LSD1-mediated silencing of a subset of RA-dependent early pancreatic genes is necessary for pancreatic progenitors to acquire competence for endocrine cell differentiation. We identified a set of LSD1-regulated genes, including many HOX genes and other genes known to be directly regulated by RA, that is transiently expressed after pancreas induction and quickly down-regulated as cells transition from the uncommitted to the endocrine-specified 
pancreatic progenitor cell stage. Several observations suggest that the mechanism by which LSD1 controls endocrine cell development is to silence these RA-regulated genes prior to endocrine cell differentiation. First, we observed that endocrine cell formation in both the hESCbased system and in mice proceeds normally when LSD1 is inhibited or deleted during endocrine cell differentiation, implying that LSD1 has no immediate role in the activation of endocrine genes.

Second, similar to LSD1 inhibition, extended exposure of uncommitted pancreatic progenitors to RA blocks endocrine cell differentiation, whereas RA exposure during endocrine cell differentiation does not. After both early LSD1 inhibition and extended RA exposure, RA-induced genes are up-regulated, which indicates that dysregulation of these genes is relevant for the phenotype. Third, Lsd1 deletion in pancreatic progenitors of mice has no effect on exocrine cell differentiation or other aspects of pancreatic development, suggesting that Lsd1-mediated silencing of these RA-regulated genes occurs specifically during endocrine lineage progression. Consistent with this notion, the expression of HOXA1 is maintained in pancreatic exocrine cells 21.

\section{Regulation of Signal-Dependent Developmental Enhancers}

Our findings suggest that the presence of LSD1 in enhancer complexes enables silencing of RAinduced genes after withdrawal of exogenous RA. In the context of LSD1 inhibition, silencing of RA-dependent genes does not occur despite RA removal, showing that absence of the RA signal is not sufficient for gene inactivation. RA is known to maintain histone acetylation by mediating recruitment of HATs, while removal of RA results in a co-factor switch leading to histone deacetylation ${ }^{20}$. Because presence of acetylated histones inhibits LSD1 activity ${ }^{9}$, LSD1-mediated enhancer decommissioning is prevented as long as RA is present, linking enhancer decommissioning and target gene silencing to RA withdrawal. Thus, presence of LSD1 in enhancer complexes provides a cell-intrinsic epigenetic mechanism that couples the duration of gene expression to the presence of the extrinsic signal. 
We show that inhibition of LSD1 activity during developmental progression coincides with increased H3K4me2/me1 deposition and increased expression of RA-dependent genes after RA removal. This raises the question of whether the catalytic activity of LSD1 and increased H3K4me2/me1 levels or demethylase-independent functions of LSD1 are responsible for the increased expression of RA-dependent genes. Our data suggest that the catalytic activity of LSD1 is indeed important, because TCP functions as an irreversible inhibitor of LSD1's catalytic activity. Furthermore, control and LSD1i ${ }^{\text {early }}$ PP2 cells exhibited no difference in LSD1 recruitment to G1 enhancers near genes up-regulated after LSD1 inhibition (data not shown). Of note, a recent study in ESCs showed that H3K4me1 is not required for transcription of nearby genes in the context of acetylated enhancers ${ }^{22}$. Our findings suggest that this is not true in the context of deacetylated enhancers, where $\mathrm{H} 3 \mathrm{~K} 4 \mathrm{me} 2 / \mathrm{me} 1$ appears to provide an enhancer activation memory that has impact on gene expression.

We find that in addition to RAR motifs, LSD1-regulated enhancers are also enriched for FOXA and SOX9 motifs (Supplementary Table 6), which are TFs with known functions in early pancreas development ${ }^{23,24}$. This indicates that regulation of early pancreatic enhancers requires collaborative interactions of signal-dependent RARs with other TFs that regulate cell identity. We have previously shown that recruitment of FOXAs to pancreas enhancers precedes pancreas induction, and occurs prior to the addition of RA during hESC differentiation ${ }^{5}$. Before RA is added, FOXA-occupied pancreatic enhancers are inactive. Combined with our present findings, this suggests that RA induces the pancreatic lineage by binding to RARs that act upon a set of primed enhancers established by FOXAs and other lineage-determining TFs. FOXAs have previously been shown to broadly prime enhancers of multiple gut tube-derived organs, including liver and lung ${ }^{5}$. While pancreas induction requires RA, lung and liver induction depend on BMP or BMP and WNT signaling, respectively. Therefore, collaboration between signal-dependent TFs and lineage-determining TFs, such as FOXAs, could be a broadly used mechanism to specify different 
organ lineages from a field of multipotent progenitors. Such mechanism is consistent with the importance of niche signals for specifying progenitor subdomains during development.

One open question is whether the here-described mechanism for LSD1-mediated enhancer silencing is limited to RA-dependent enhancers or could operate also in the context of other signal-dependent enhancers. LSD1 has been shown to reside in transcriptional complexes with signal-dependent TFs of numerous signalling pathways, including the Notch, Wnt, and multiple nuclear hormone receptor signalling pathways ${ }^{25-27}$. Similar to RARs, which associate with HATs upon RA binding ${ }^{20}$, the Notch intracellular domain facilitates recruitment of HATs to Notch-responsive enhancers in the presence of ligand, and $\beta$-catenin recruits HATs when the Wnt signalling pathway is activated ${ }^{28,29}$. It is therefore conceivable that LSD1 limits the duration of a transcriptional response at these enhancers in a similar manner as shown in this study for RAresponsive enhancers. Such unified mechanism for LSD1 function would explain why LSD1 activity is required in numerous development contexts throughout phylogeny ${ }^{30-34}$. 


\section{Methods}

\section{Cell lines and animal models}

\section{Cell Lines}

CyT49 embryonic stem cells were maintained in DMEM F12 (without L-glutamine; VWR) + 10\% knockout serum replacement (KSR; Thermo Fisher Scientific), 1\% non-essential amino acids (NEAA; Thermo Fisher Scientific), $1 \%$ GlutaMAX (Thermo Fisher Scientific), $0.2 \% \quad \beta-$ mercaptoethanol (Thermo Fisher Scientific) and 1\% penicillin-streptomycin (Thermo Fisher Scientific).

\section{Animals}

Pdx1-Cre, Pdx1-CreER ${ }^{\mathrm{TM}}{ }^{35}$ and $L s d 1^{\text {flox } 30}$ mouse strains have been described previously. $L s d 1^{\Delta \text { pan }}$ mice were generated by crossing $P d x 1-C r e$ and $L s d 1^{\text {flox }}$ mice. Conditional $L s d 1$ knockouts were generated by crossing $P d x 1-C r e E R^{\mathrm{TM}}$ and $L s d 1^{\text {flox }}$ mice. Tamoxifen (Sigma) was dissolved in corn oil (Sigma) at $10 \mathrm{mg} / \mathrm{mL}$, and a single dose of $3.5 \mathrm{mg} / 40 \mathrm{~g}$ or $4.5 \mathrm{mg} / 40 \mathrm{~g}$ body weight was administered by intraperitoneal injection at embryonic day (e) 10.5 or e12.5, respectively. Control mice were $\mathrm{LSD}^{+/+}$littermates carrying the $P d x 1-C r e$ or the $P d x 1-C r e E R^{\mathrm{TM}}$ transgene. Midday on the day of vaginal plug appearance was considered embryonic day (e) 0.5. All animal experiments were approved by the Institutional Animal Care and Use Committees of the University of California, San Diego. The numbers of animals studied per genotype are indicated within each experiment.

\section{Human Tissue}

Human foetal pancreas donor tissue was obtained from the Birth Defects Research Laboratory of the University of Washington. Cadaveric adult pancreata used in this study were from non-diabetic donors and were acquired through the Network for Pancreatic Organ Donors with Diabetes 
(nPOD) ${ }^{36}$. Protein expression was analyzed in nPOD donors: LSD1 and GCG in \#6140 (38-yearold male); LSD1 and CHGA in \#6160 (22-year-old male); LSD1 and SST in 6178 (25-year-old female); and LSD1, INS and GCG in 6179 (21-year-old female).

\section{Experimental Methods and Data Analysis}

\section{Pancreatic Endocrine Differentiation of Human Embryonic Stem Cells (hESCs)}

Pancreatic differentiation was performed as previously described ${ }^{5,12,14}$. Briefly, a suspensionbased culture format was used to differentiate cells in aggregate form. Undifferentiated aggregates of hESCs were formed by re-suspending dissociated cells in hESC maintenance medium at a concentration of $1 \times 10^{6}$ cells $/ \mathrm{mL}$ and plating $5.5 \mathrm{~mL}$ per well of the cell suspension in 6-well ultra-low attachment plates (Costar). The cells were cultured overnight on an orbital rotator (Innova2000, New Brunswick Scientific) at $95 \mathrm{rpm}$. After 24 hours the undifferentiated aggregates were washed once with RPMI medium and supplied with $5.5 \mathrm{~mL}$ of day 0 differentiation medium. Thereafter, cells were supplied with the fresh medium for the appropriate day of differentiation (see below). Cells were continually rotated at $95 \mathrm{rpm}$, or $105 \mathrm{rpm}$ on days 4 through 8, and no media change was performed on day 10. Both RPMI (Mediatech) and DMEM High Glucose (HyClone) medium were supplemented with $1 \mathrm{X}$ GlutaMAX ${ }^{\mathrm{TM}}$ and $1 \%$ penicillin/streptomycin. Human activin A, mouse Wnt3a, human KGF, human noggin, and human EGF were purchased from R\&D systems. Other added components included FBS (HyClone), B27® supplement (Life Technologies), Insulin-Transferrin-Selenium (ITS; Life Technologies), TGF $\beta$ R1 kinase inhibitor IV (EMD Bioscience), KAAD-Cyclopamine (KC; Toronto Research Chemicals), and the retinoic receptor agonist TTNPB (RA; Sigma Aldrich). Day-specific differentiation media formulations were as follows: Days 0 and 1: RPMI $+0.2 \%(v / v)$ FBS, 100 $\mathrm{ng} / \mathrm{mL}$ Activin, $50 \mathrm{ng} / \mathrm{mL}$ mouse Wnt3a, 1:5000 ITS. Days 1 and 2: RPMI + 0.2\% (v/v) FBS, 100ng/mL Activin, 1:5000 ITS. Days 2 and 3: RPMI + 0.2\% (v/v) FBS, 2.5 mM TGF $\beta$ R1 kinase inhibitor IV, 25ng/mL KGF, 1:1000 ITS. Days 3 - 5: RPMI + 0.2\% (v/v) FBS, 25ng/mL KGF, 1:1000 
ITS. Days 5 - 8: DMEM + 0.5X B-27® Supplement, 3 nM TTNPB, 0.25 mM KAAD-Cyclopamine, 50ng/mL Noggin. Days 8 - 12: DMEM/B27, 50ng/mL KGF, 50ng/mL EGF.

\section{LSD1 Inhibition during Pancreatic Differentiation}

Early inhibition of LSD1 (LSD1 $\mathrm{i}^{\text {early }}$ ) was performed by addition of the irreversible LSD1 inhibitor tranylcypromine (TCP) to cell culture wells on days 7,8 and 9 at a final concentration of $0.5 \mu \mathrm{M}$. Late inhibition of LSD1 (LSD1ilate $)$ was performed by addition of TCP to cell culture wells on days 10,11 and 12 at a final concentration of $0.5 \mu \mathrm{M}$. Additional LSD1 inhibitors used to perform LSD1i ${ }^{\text {early }}$ and LSD1ilate experiments were SP2509 (Selleck Chemicals), GSK-LSD1 (Sigma) and GSK2879552 (Chemietek); and experiments were performed in the same way as with TCP, at a final concentrations of $1 \mu \mathrm{M}$.

\section{Alteration of RA Treatment during Pancreatic Differentiation}

Extended RA treatment $\left(\mathrm{RA}^{\text {extended }}\right)$ was performed by addition of the RA analogue TTNPB to cell culture wells on days 8 and 9 at a final concentration of $3 \mathrm{nM}$. Late RA treatment $\left(\mathrm{RA}^{\text {late }}\right)$ was performed by addition of TTNPB to cell culture wells on days 10 and 11 at a final concentration of $3 \mathrm{nM}$.

\section{Chromatin Immunoprecipitation Sequencing (ChIP-seq)}

ChIP-seq was performed using the ChIP-IT High-Sensitivity kit (Active Motif) according to the manufacturer's instructions. Briefly, for each cell stage and condition analyzed, $5-10 \times 10^{6}$ cells were harvested and fixed for $15 \mathrm{~min}$ in an $11.1 \%$ formaldehyde solution. Cells were lysed and homogenised using a Dounce homogeniser and the lysate was sonicated in a Bioruptor ${ }^{\circledR}$ Plus (Diagenode), on high for $3 \times 5 \mathrm{~min}$ (30 sec on, $30 \mathrm{sec}$ off). Between 10 and $30 \mu \mathrm{g}$ of the resulting sheared chromatin was used for each immunoprecipitation. Equal quantities of sheared chromatin from each sample were used for immunoprecipitations carried out at the same time. $4 \mu \mathrm{g}$ of 
antibody were used for each ChIP-seq assay. Chromatin was incubated with primary antibodies overnight at $4{ }^{\circ} \mathrm{C}$ on a rotator followed by incubation with Protein $\mathrm{G}$ agarose beads for 3 hours at $4{ }^{\circ} \mathrm{C}$ on a rotator. Reversal of crosslinks and DNA purification were performed according to the ChIP-IT High-Sensitivity instructions, with the modification of incubation at $65{ }^{\circ} \mathrm{C}$ for $2-3$ hours, rather than at $80^{\circ} \mathrm{C}$ for 2 hours. Sequencing libraries were constructed using KAPA DNA Library Preparation Kits for Illumina ${ }^{\circledR}$ (Kapa Biosystems) and library sequencing was performed on a HiSeq 4000 System (Illumina ${ }^{\circledR}$ ) with single-end reads of 50 base pairs (bp). Both library construction and sequencing were performed by the Institute for Genomic Medicine (IGM) core research facility at the University of California at San Diego (UCSD). Two biological replicates were generated for each ChIP-seq experiment.

\section{ChIP-seq Data Analysis}

Single-end 50-bp ChIP-seq reads were mapped to the human genome consensus build (hg19/GRCh37) and visualised using the UCSC Genome Browser ${ }^{37}$. Bowtie 2, version $2.2 .7^{38}$ was used to map data to the genome and unmapped reads were discarded. SAMtools ${ }^{39}$ was used to remove duplicate sequences and HOMER ${ }^{40}$ was used to call peaks using default parameters and to generate tag density plots. Stage- and condition-matched input DNA controls were used as background when calling peaks. The BEDtools ${ }^{41}$ suite of programs was used to analyze whether certain peaks overlapped with other peaks or modified histone regions. Differential peak analysis using HOMER, with default parameters, identified enhancer dynamics between the PP1 to PP2 stage and classify LSD1-bound enhancers into the different enhancer groups (G1, G2 and G3). Each ChIP-seq analysis was performed with two biological replicates, except H3K4me2 at GT, for which pseudo-replicates were generated. The first replicate was analyzed and correlated with the appropriate second replicate. Pearson correlations between replicates are as follows: 


\begin{tabular}{|c|c|c|c|c|}
\hline Condition & LSD1 & H3K27ac & H3K4me1 & H3K4me2 \\
\hline GT & N/A & 0.81 & 0.95 & 0.94 \\
\hline PP1 & 0.80 & 0.84 & 0.91 & 0.99 \\
\hline PP2 & 0.74 & 0.88 & 0.80 & 0.99 \\
\hline $\begin{array}{c}\text { PP2 } \\
\text { LSD1i }^{\text {early }}\end{array}$ & 0.82 & 0.88 & 0.81 & 0.94 \\
\hline
\end{tabular}

\section{RNA Isolation and Sequencing (RNA-seq) and qRT-PCR}

RNA was isolated from cell samples using the RNeasy ${ }^{\circledR}$ Micro Kit (Qiagen) according to the manufacturer instructions. For each cell stage and condition analyzed between 0.1 and $1 \times 10^{6}$ cells were collected for RNA extraction. For qRT-PCR, cDNA synthesis was first performed using the iScript ${ }^{\mathrm{TM}}$ cDNA Synthesis Kit (Bio-Rad) and $500 \mathrm{ng}$ of isolated RNA per reaction. qRT-PCR reactions were performed in triplicate with $10 \mathrm{ng}$ of template cDNA per reaction using a CFX96 ${ }^{\mathrm{TM}}$ Real-Time PCR Detection System and the $\mathrm{iQ}^{\mathrm{TM}} \mathrm{SYBR}^{\circledR}$ Green Supermix (Bio-Rad). PCR of the TATA binding protein (TBP) coding sequence was used as an internal control and relative expression was quantified via double delta $C_{\mathrm{T}}$ analysis. For RNA-seq, stranded, single-end sequencing libraries were constructed from isolated RNA using the TruSeq $^{\circledR}$ Stranded mRNA Library Prep Kit (Illumina $^{\circledR}$ ) and library sequencing was performed on a HiSeq 4000 System (Illumina $^{\circledR}$ ) with single-end reads of $50-\mathrm{bp}$. Both library construction and sequencing were performed by the IGM core research facility at UCSD. A complete list of RT-qPCR primer sequences can be found below.

\begin{tabular}{|l|l|}
\hline $\begin{array}{l}\text { Primer } \\
\text { Name }\end{array}$ & Sequence \\
\hline INS-F & AAGAGGCCATCAAGCAGATCA \\
\hline INS-R & CAGGAGGCGCATCCACA \\
\hline GCG-F & $\begin{array}{l}\text { AAGCATTTACTTTGTGGCTGGAT } \\
\text { T }\end{array}$ \\
\hline GCG-R & $\begin{array}{l}\text { TGATCTGGATTTCTCCTCTGTGT } \\
\text { CT }\end{array}$ \\
\hline HOXA1-F & CGGAACTGGAGAAGGAGTTC \\
\hline HOXA1-R & TTCACTTGGGTCTCGTTGAG \\
\hline SST-F & CCCCAGACTCCGTCAGTTTC \\
\hline SST-R & TCCGTCTGGTTGGGTTCAG \\
\hline
\end{tabular}




\begin{tabular}{|l|l|}
\hline TBP-F & ATTAAGGGAGGGAGTGGCAC \\
\hline TBP-R & GCTTTGCTTCCCTTTCCCAA \\
\hline
\end{tabular}

\section{RNA-seq Data Analysis}

Single-end 50-bp reads were mapped to the human genome consensus build (hg19/GRCh37) using the Spliced Transcripts Alignment to a Reference (STAR) aligner ${ }^{42}$. Tag directories were constructed from STAR outputs and normalised gene expression (fragments per kilobase per million mapped reads; FPKM) for each sequence file was determined using HOMER ${ }^{40}$. HOMER was used to annotate all RefSeq genes with FPKM values and to invoke the R package DESeq2 ${ }^{43}$ for differential expression analysis. Each RNA-seq analysis was performed on at least two biological replicates with DESeq2, using the built-in option to account for batch effects.

\section{Assignment of Enhancer Target Genes and Motif Enrichment Analysis}

Enhancer target genes were assigned using BEDtools to identify transcription start sites (TSSs) located $\pm 100 \mathrm{~kb}$ from LSD1-bound enhancers (groups $\mathrm{G} 1, \mathrm{G} 2$ and G3). HOMER ${ }^{40}$ was used to identify transcription factor (TF) binding motifs enriched in the G1 enhancer group versus the G2 and G3 groups. G2 and G3 enhancer peak files were merged and set as the background. G1 enhancers associated with one or more genes with FPKM $\geq 1$ at the PP1 stage were used for motif analysis.

\section{Immunofluorescence Analysis}

Cell aggregates derived from hESCs were allowed to settle in microcentrifuge tubes and washed twice with PBS before fixation with 4\% paraformaldehyde (PFA) for 30 min at room temperature. Dissected e10.5 - e13.5 mouse embryos, e15.5 - postnatal day $(P) 0$ pancreata, and pancreata from 3-month-old mice were fixed in 4\% PFA in PBS for 30 minutes, 3 hours, and overnight, respectively. Fixed samples were washed twice with PBS and incubated overnight at $4{ }^{\circ} \mathrm{C}$ in $30 \%$ $(w / v)$ sucrose in PBS. Samples were then loaded into disposable embedding molds (VWR), 
covered in Tissue-Tek® O.C.T. Sakura ${ }^{\circledR}$ Finetek compound (VWR) and flash frozen on dry ice to prepare frozen blocks. The blocks were sectioned at $10 \mu \mathrm{m}$ and sections were placed on Superfrost Plus ${ }^{\circledR}$ (Thermo Fisher) microscope slides and washed with PBS for 10 min. Slidemounted cell sections were permeabilised and blocked with blocking buffer, consisting of $0.15 \%$ (v/v) Triton X-100 (Sigma) and 1\% (v/v) normal donkey serum (Jackson Immuno Research Laboratories) in PBS, for 1 hour at room temperature. Slides were then incubated overnight at 4 ${ }^{\circ} \mathrm{C}$ with primary antibody solutions. The following day slides were washed five times with PBS and incubated for 1 hour at room temperature with secondary antibody solutions. Cells were washed five times with PBS before coverslips were applied.

All antibodies were diluted in blocking buffer at the ratios indicated below. Primary antibodies used were: goat anti-carboxypeptidase A1 (Cpa1) (1:1000 dilution, R\&D systems); goat anti-ghrelin (Ghrl) (1:300 dilution, Santa Cruz); goat anti-glucagon (Gcg) (1:1000 dilution, Santa Cruz); goat anti-osteopontin (Opn) (1:300 dilution, R\&D systems); goat anti-PDX1 (1:500 dilution, Abcam); guinea pig anti-insulin (INS) (1:500 dilution, Dako); mouse anti-glucagon (GCG) (1:500 dilution, Sigma); rabbit anti-somatostatin (SST) (1:500 dilution, Dako); mouse anti-NKX6.1 (1:300 dilution, Developmental Studies Hybridoma Bank); rabbit anti-amylase (Amy) (1:500 dilution, Sigma); rabbit anti-chromogranin A (ChgA) (1:1000 dilution, Dako); rabbit anti-LSD1 (1:500 dilution, Abcam); rabbit anti-Phospo-Histone3 (Ser10) (pHH3) (1:1000 dilution, Cell Signaling); rabbit anti-polypeptide Y (Ppy) (1:1000 dilution, Dako); rabbit anti-Ptf1a (1:500 dilution, BCBC); rabbit anti-SOX9 (1:1000 dilution, Millipore); rat anti-E-cadherin (Cdh1) (1:300 dilution, Sigma). Secondary antibodies against sheep, rabbit, goat, mouse and guinea pig were Alexa488, Cy3- and Cy5-conjugated donkey antibodies and were used at dilutions of 1:1000, 1:2000, and 1:250, respectively (Jackson Immuno Research Laboratories). Cell nuclei were stained with Hoechst 33342 (1:3000, Invitrogen). TUNEL staining was performed using the ApopTag® Plus Peroxidase In Situ Apoptosis Kit (Millipore). Representative images were obtained with a Zeiss 
Axio-Observer-Z1 microscope equipped with a Zeiss ApoTome and AxioCam digital camera. Figures were prepared in Adobe Creative Suite 5.

\section{Flow Cytometry Analysis}

Cell aggregates derived from hESCs were allowed to settle in microcentrifuge tubes and washed with PBS. Cell aggregates were incubated with Accutase ${ }^{\circledR}$ at room temperature until a single-cell suspension was obtained. Cells were washed with $1 \mathrm{~mL}$ ice-cold flow buffer comprised of $0.2 \%$ BSA in PBS and centrifuged at $200 \mathrm{~g}$ for $5 \mathrm{~min}$. BD Cytofix/Cytoperm ${ }^{\mathrm{TM}}$ Plus Fixation/Permeabilization Solution Kit was used to fix and stain cells for flow cytometry according to the manufacturer's instructions. Briefly, cell pellets were re-suspended in ice-cold BD Fixation/Permeabilization solution (300 $\mu \mathrm{L}$ per microcentrifuge tube). Cells were incubated for 20 min at $4{ }^{\circ} \mathrm{C}$. Cells were washed twice with $1 \mathrm{~mL}$ ice-cold $1 \mathrm{X}$ BD Perm/Wash ${ }^{\mathrm{TM}}$ Buffer and centrifuged at $10{ }^{\circ} \mathrm{C}$ and $200 \times \mathrm{g}$ for $5 \mathrm{~min}$. Cells were re-suspended in $50 \mu \mathrm{L}$ ice-cold $1 \mathrm{X}$ BD Perm/Wash ${ }^{\mathrm{TM}}$ Buffer containing diluted antibodies, for each staining performed. Cells were incubated at $4{ }^{\circ} \mathrm{C}$ in the dark for $1 \mathrm{hr}$. Cells were washed with $1.25 \mathrm{~mL}$ ice-cold $1 \mathrm{X}$ BD Wash Buffer and centrifuged at $200 \mathrm{~g}$ for $5 \mathrm{~min}$. Cell pellets were re-suspended in $300 \mu \mathrm{L}$ ice-cold flow buffer and analysed in a FACSCanto ${ }^{\mathrm{TM}}$ (BD Biosciences). Antibodies used for flow cytometry: PE-conjugated anti-PDX1 (1:20 dilution, BD Biosciences); AlexaFluor $§$ 647-conjugated antiNKX6.1 (1:20 dilution, BD Biosciences); PE-conjugated anti-INS (1:50 dilution, BD Biosciences).

\section{Gene Ontology}

Gene ontology analysis was performed using Metascape (http://metscape.ncibi.org) with the default parameters.

\section{Quantification and Statistical Analysis}

\section{Morphometric Analysis and Cell Counting}


At e12.5, every pancreas section was analysed from a minimum of three embryos per genotype, while every fifth pancreas section was analysed at e15.5. For determination of total pancreatic epithelial area, E-cadherin ${ }^{+}$area per section was measured using ZEN Digital Imaging for Light Microscopy software (ZEISS), which was calibrated to calculate values in $\mu m^{2}$. The number of marker ${ }^{+}$cells was determined by counting every marker ${ }^{+} / \mathrm{DAPI}^{+}$cell in each section. The number of marker ${ }^{+}$cells per section was subsequently divided by the total epithelial area of the section and expressed as marker ${ }^{+}$cells $/ \mu m^{2}$. All values are shown as mean \pm standard error of the mean (SEM); $p$-values calculated using unpaired Student's t-test; $p<0.05$ was considered significant.

\section{Experimental Comparisons}

All experiments were independently repeated at least twice. Results are shown as mean \pm SEM. Statistical analyses were conducted using GraphPad Prism 6 and R.

\section{Differential Gene Expression Analysis}

The DESeq2 Bioconductor package for $\mathrm{R}$ was used to calculate gene expression changes. Adjusted $p$-values $<0.05$ and $\log _{2}($ fold-change $) \geq 1.5$ were considered significantly different.

\section{Permutation-Based Significance}

A random sampling approach (10,000 iterations) was used to obtain null distributions for enrichment analyses, in order to obtain p-values. Null distributions for enrichment of enhancers for gene sets were obtained by randomly shuffling enhancer regions using BEDtools and overlapping with nearby genes. P-values $<0.05$ were considered significant.

\section{Data Availability}

The accession number for the ChIP-seq and RNA-seq data reported in this manuscript is GSE104840. The accession number for previously reported H3K4me1 and H3K27ac ChIP-seq 
bioRxiv preprint doi: https://doi.org/10.1101/716647; this version posted August 1, 2019. The copyright holder for this preprint (which was not certified by peer review) is the author/funder. All rights reserved. No reuse allowed without permission.

data is GSE54471. The accession number for previously reported RNA-seq data is E-MTAB1086. 


\section{Acknowledgements}

We thank FenFen Liu, Nancy Rosenblatt, and Thomas Harper for experimental assistance, the Sander laboratory for helpful discussions and comments on the manuscript. We are grateful to Tung Nguyen, Rizi Ai and Wei Wang for help with data analysis at early stages of this project and Sven Heinz for advice with ChIP-seq experiments. We acknowledge support of the UCSD Human Embryonic Stem Cell Core for cell sorting and the UCSD IGM Genomic Center (supported by P30 DK064391) for library preparation and sequencing. This work was supported by a California Institute for Regenerative Medicine (CIRM) training grant (N.A.P.), Juvenile Diabetes Research Foundation postdoctoral fellowships (H.P.S., A.W.), and by National Institutes of Health grants DK089567 and DK068471, and CIRM grant RB5-07236 (M.S.).

\section{Author Contributions}

N.K.V., N.A.P., A.W., and M.S. conceived the project and designed the experiments. N.K.V., N.A.P., and Jinzhao W. performed experiments. N.K.V. and C.W.B. analysed sequencing data. Jianxun W. and M.G.R. provided mice. H.P.S. and U.S.J. provided technical expertise and critical suggestions for experimental design. N.K.V., N.A.P., A.W., and M.S. interpreted data. N.K.V., N.A.P., and M.S. wrote the manuscript.

\section{Competing Interests}

The authors declare no competing interests. 


\section{References}

$1 \quad$ Huang, W. et al. Retinoic acid plays an evolutionarily conserved and biphasic role in pancreas development. Developmental biology 394, 83-93, doi:10.1016/j.ydbio.2014.07.021 (2014).

2 Buecker, C. \& Wysocka, J. Enhancers as information integration hubs in development: lessons from genomics. Trends in genetics : TIG 28, 276-284, doi:10.1016/j.tig.2012.02.008 (2012).

3 Rada-lglesias, A. et al. A unique chromatin signature uncovers early developmental enhancers in humans. Nature 470, 279-283, doi:10.1038/nature09692 (2011).

4 Creyghton, M. P. et al. Histone H3K27ac separates active from poised enhancers and predicts developmental state. Proceedings of the National Academy of Sciences of the United States of America 107, 21931-21936, doi:10.1073/pnas.1016071107 (2010).

$5 \quad$ Wang, A. et al. Epigenetic priming of enhancers predicts developmental competence of hESCderived endodermal lineage intermediates. Cell Stem Cell 16, 386-399, doi:10.1016/j.stem.2015.02.013 (2015).

6 Heinz, S., Romanoski, C. E., Benner, C. \& Glass, C. K. The selection and function of cell typespecific enhancers. Nature reviews. Molecular cell biology 16, 144-154, doi:10.1038/nrm3949 (2015).

7 Shi, Y. et al. Histone demethylation mediated by the nuclear amine oxidase homolog LSD1. Cell 119, 941-953, doi:10.1016/j.cell.2004.12.012 (2004).

$8 \quad$ Whyte, W. A. et al. Enhancer decommissioning by LSD1 during embryonic stem cell differentiation. Nature 482, 221-225, doi:10.1038/nature10805 (2012).

9 Shi, Y. J. et al. Regulation of LSD1 histone demethylase activity by its associated factors. Molecular cell 19, 857-864, doi:10.1016/j.molcel.2005.08.027 (2005).

10 Metzger, E. et al. LSD1 demethylates repressive histone marks to promote androgen-receptordependent transcription. Nature 437, 436-439, doi:10.1038/nature04020 (2005).

11 Lee, M. G., Wynder, C., Cooch, N. \& Shiekhattar, R. An essential role for CoREST in nucleosomal histone 3 lysine 4 demethylation. Nature 437, 432-435, doi:10.1038/nature04021 (2005).

12 Xie, R. et al. Dynamic chromatin remodeling mediated by polycomb proteins orchestrates pancreatic differentiation of human embryonic stem cells. Cell Stem Cell 12, 224-237, doi:10.1016/j.stem.2012.11.023 (2013).

13 D'Amour, K. A. et al. Production of pancreatic hormone-expressing endocrine cells from human embryonic stem cells. Nature biotechnology 24, 1392-1401, doi:10.1038/nbt1259 (2006).

14 Schulz, T. C. et al. A scalable system for production of functional pancreatic progenitors from human embryonic stem cells. PloS one 7, e37004, doi:10.1371/journal.pone.0037004 (2012). Zentner, G. E. \& Scacheri, P. C. The chromatin fingerprint of gene enhancer elements. The Journal of biological chemistry 287, 30888-30896, doi:10.1074/jbc.R111.296491 (2012). Heintzman, N. D. et al. Histone modifications at human enhancers reflect global cell-type-specific gene expression. Nature 459, 108-112, doi:10.1038/nature07829 (2009).

17 Wang, J. et al. Novel histone demethylase LSD1 inhibitors selectively target cancer cells with pluripotent stem cell properties. Cancer research 71, 7238-7249, doi:10.1158/0008-5472.CAN11-0896 (2011).

18 Martin, M. et al. Dorsal pancreas agenesis in retinoic acid-deficient Raldh2 mutant mice. Developmental biology 284, 399-411, doi:10.1016/j.ydbio.2005.05.035 (2005).

19 Stafford, D. \& Prince, V. E. Retinoic acid signaling is required for a critical early step in zebrafish pancreatic development. Curr Biol 12, 1215-1220 (2002).

20 Cunningham, T. J. \& Duester, G. Mechanisms of retinoic acid signalling and its roles in organ and limb development. Nature reviews. Molecular cell biology 16, 110-123, doi:10.1038/nrm3932 (2015).

21 Lomberk, G. A., Imoto, I., Gebelein, B., Urrutia, R. \& Cook, T. A. Conservation of the TGFbeta/Labial homeobox signaling loop in endoderm-derived cells between Drosophila and mammals. Pancreatology 10, 74-84, doi:10.1159/000276895 (2010).

22 Dorighi, K. M. et al. MII3 and MII4 Facilitate Enhancer RNA Synthesis and Transcription from Promoters Independently of H3K4 Monomethylation. Molecular cell 66, 568-576 e564, doi:10.1016/j.molcel.2017.04.018 (2017). 
23 Gao, N. et al. Dynamic regulation of Pdx1 enhancers by Foxa1 and Foxa2 is essential for pancreas development. Genes Dev 22, 3435-3448, doi:10.1101/gad.1752608 (2008).

24 Shih, H. P. et al. A Gene Regulatory Network Cooperatively Controlled by Pdx1 and Sox9 Governs Lineage Allocation of Foregut Progenitor Cells. Cell Rep 13, 326-336, doi:10.1016/j.celrep.2015.08.082 (2015).

25 Cai, C. et al. Lysine-specific demethylase 1 has dual functions as a major regulator of androgen receptor transcriptional activity. Cell Rep 9, 1618-1627, doi:10.1016/j.celrep.2014.11.008 (2014). Choi, S. H., Estaras, C., Moresco, J. J., Yates, J. R., 3rd \& Jones, K. A. alpha-Catenin interacts with APC to regulate beta-catenin proteolysis and transcriptional repression of Wnt target genes. Genes Dev 27, 2473-2488, doi:10.1101/gad.229062.113 (2013).

27 Mulligan, P. et al. A SIRT1-LSD1 corepressor complex regulates Notch target gene expression and development. Molecular cell 42, 689-699, doi:10.1016/j.molcel.2011.04.020 (2011).

28 Kitagawa, M. Notch signalling in the nucleus: roles of Mastermind-like (MAML) transcriptional coactivators. J Biochem 159, 287-294, doi:10.1093/jb/mvv123 (2016).

29 Novellasdemunt, L., Antas, P. \& Li, V. S. Targeting Wnt signaling in colorectal cancer. A Review in the Theme: Cell Signaling: Proteins, Pathways and Mechanisms. Am J Physiol Cell Physiol 309, C511-521, doi:10.1152/ajpcell.00117.2015 (2015).

30 Wang, J. et al. Opposing LSD1 complexes function in developmental gene activation and repression programmes. Nature 446, 882-887, doi:10.1038/nature05671 (2007).

31 Popova, E. Y., Pinzon-Guzman, C., Salzberg, A. C., Zhang, S. S. \& Barnstable, C. J. LSD1Mediated Demethylation of H3K4me2 Is Required for the Transition from Late Progenitor to Differentiated Mouse Rod Photoreceptor. Mol Neurobiol 53, 4563-4581, doi:10.1007/s12035-0159395-8 (2016).

32 Kerenyi, M. A. et al. Histone demethylase Lsd1 represses hematopoietic stem and progenitor cell signatures during blood cell maturation. eLife 2, e00633, doi:10.7554/eLife.00633 (2013).

33 Di Stefano, L., Ji, J. Y., Moon, N. S., Herr, A. \& Dyson, N. Mutation of Drosophila Lsd1 disrupts H3-K4 methylation, resulting in tissue-specific defects during development. Curr Biol 17, 808-812, doi:10.1016/j.cub.2007.03.068 (2007).

34 Katz, D. J., Edwards, T. M., Reinke, V. \& Kelly, W. G. A C. elegans LSD1 demethylase contributes to germline immortality by reprogramming epigenetic memory. Cell 137, 308-320, doi:10.1016/j.cell.2009.02.015 (2009).

35 Gu, G., Dubauskaite, J. \& Melton, D. A. Direct evidence for the pancreatic lineage: NGN3+ cells are islet progenitors and are distinct from duct progenitors. Development 129, 2447-2457 (2002).

36 Campbell-Thompson, M. et al. Network for Pancreatic Organ Donors with Diabetes (nPOD): developing a tissue biobank for type 1 diabetes. Diabetes/metabolism research and reviews 28, 608-617, doi:10.1002/dmrr.2316 (2012).

37 Kent, W. J. et al. The human genome browser at UCSC. Genome research 12, 996-1006, doi:10.1101/gr.229102. Article published online before print in May 2002 (2002).

38 Langmead, B. \& Salzberg, S. L. Fast gapped-read alignment with Bowtie 2. Nat Methods 9, 357359, doi:10.1038/nmeth.1923 (2012).

$39 \mathrm{Li}, \mathrm{H}$. et al. The Sequence Alignment/Map format and SAMtools. Bioinformatics 25, 2078-2079, doi:10.1093/bioinformatics/btp352 (2009).

40 Heinz, S. et al. Simple combinations of lineage-determining transcription factors prime cisregulatory elements required for macrophage and B cell identities. Molecular cell 38, 576-589, doi:10.1016/j.molcel.2010.05.004 (2010).

41 Quinlan, A. R. \& Hall, I. M. BEDTools: a flexible suite of utilities for comparing genomic features. Bioinformatics 26, 841-842, doi:10.1093/bioinformatics/btq033 (2010).

42 Dobin, A. et al. STAR: ultrafast universal RNA-seq aligner. Bioinformatics 29, 15-21, doi:10.1093/bioinformatics/bts635 (2013).

43 Love, M. I., Huber, W. \& Anders, S. Moderated estimation of fold change and dispersion for RNAseq data with DESeq2. Genome Biol 15, 550, doi:10.1186/s13059-014-0550-8 (2014). 
a

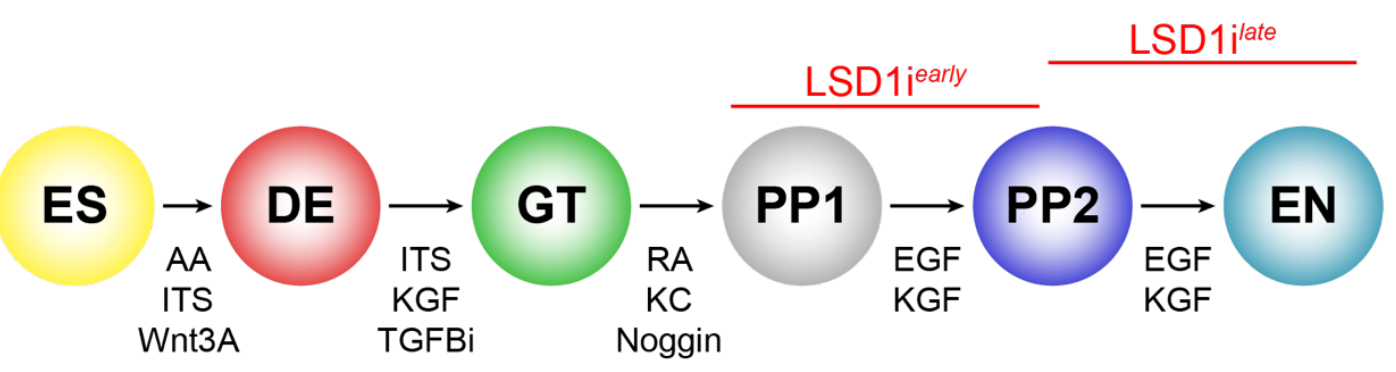

b

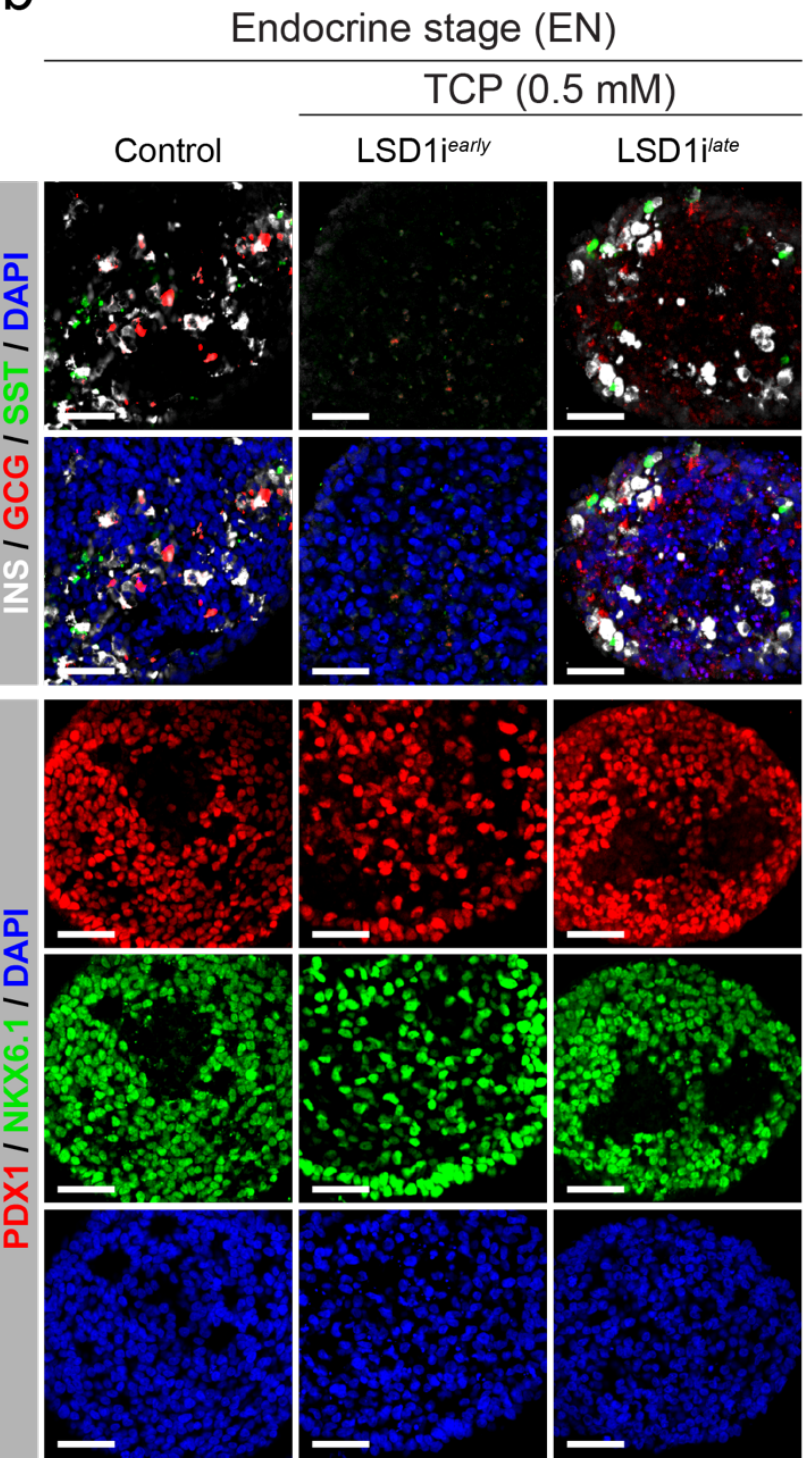

C Endocrine stage (EN)

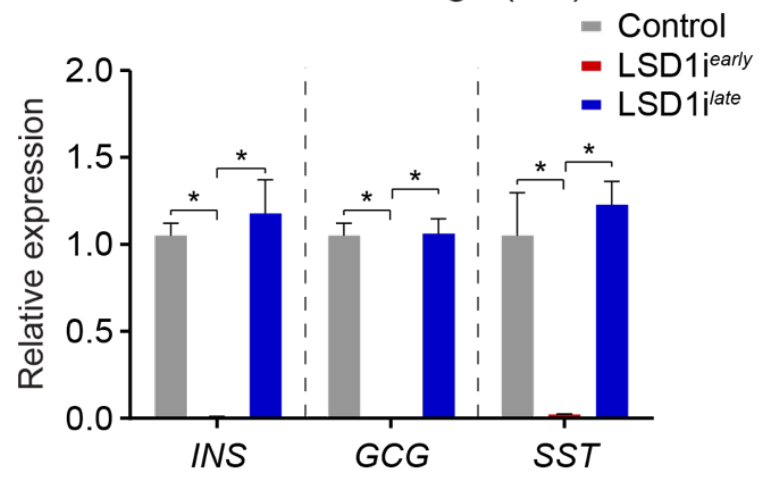

d Endocrine stage (EN)

-antibody -isotype

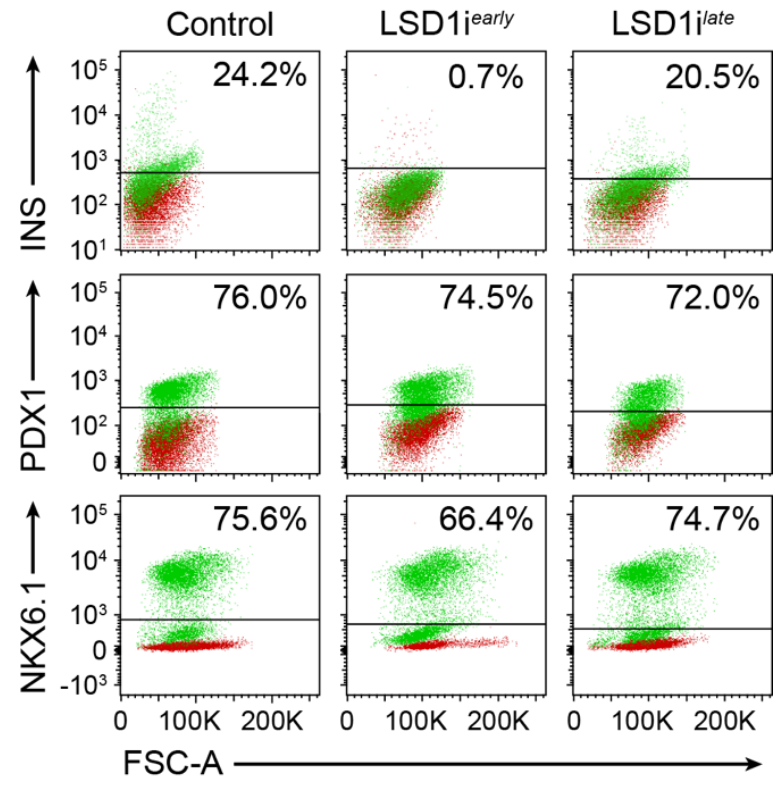


Figure 1. Endocrine cell formation requires LSD1 activity during a short window in early pancreatic development. a, Schematic of the human embryonic stem cell (hESC) differentiation protocol to the endocrine cell stage $(E N)$ and experimental plan for LSD1 inhibition. b, Immunofluorescent staining for pancreatic hormones insulin (INS), glucagon (GCG) and somatostatin (SST) or PDX1 and NKX6.1 in control EN cells compared to EN cells with early (LSD1i ${ }^{\text {early }}$ ) and late (LSD1ilate) LSD1 inhibition. Scale bar, $50 \mu \mathrm{m}$. c, qRT-PCR analysis for INS, GCG and SST in control, LSD1i ${ }^{\text {early }}$ and LSD1i late EN cells. Data are shown as mean \pm S.E.M. (n $=2$ biological replicates). ${ }^{*} p<0.05$, Student's t-test. $\mathbf{d}$, Flow cytometry analysis at EN stage for NKX6.1, PDX1 and INS comparing control, LSD1iearly and LSD1ilate cells. Isotype control for each antibody is shown in red and target protein staining in green. Percentage of cells expressing each protein is indicated (representative experiment, $n=2$ ). AA, activin $A$; ITS, insulin-transferrinselenium; TGFBi, TGF $\beta$ R1 kinase inhibitor; KC, KAAD-cyclopamine; KGF, keratinocyte growth factor; RA, retinoic acid; EGF, epidermal growth factor; ES, human embryonic stem cells; DE, definitive endoderm; GT, primitive gut tube; PP1, early pancreatic progenitors; PP2, late pancreatic progenitors; EN, endocrine cell stage; FSC-A, forward scatter area. 

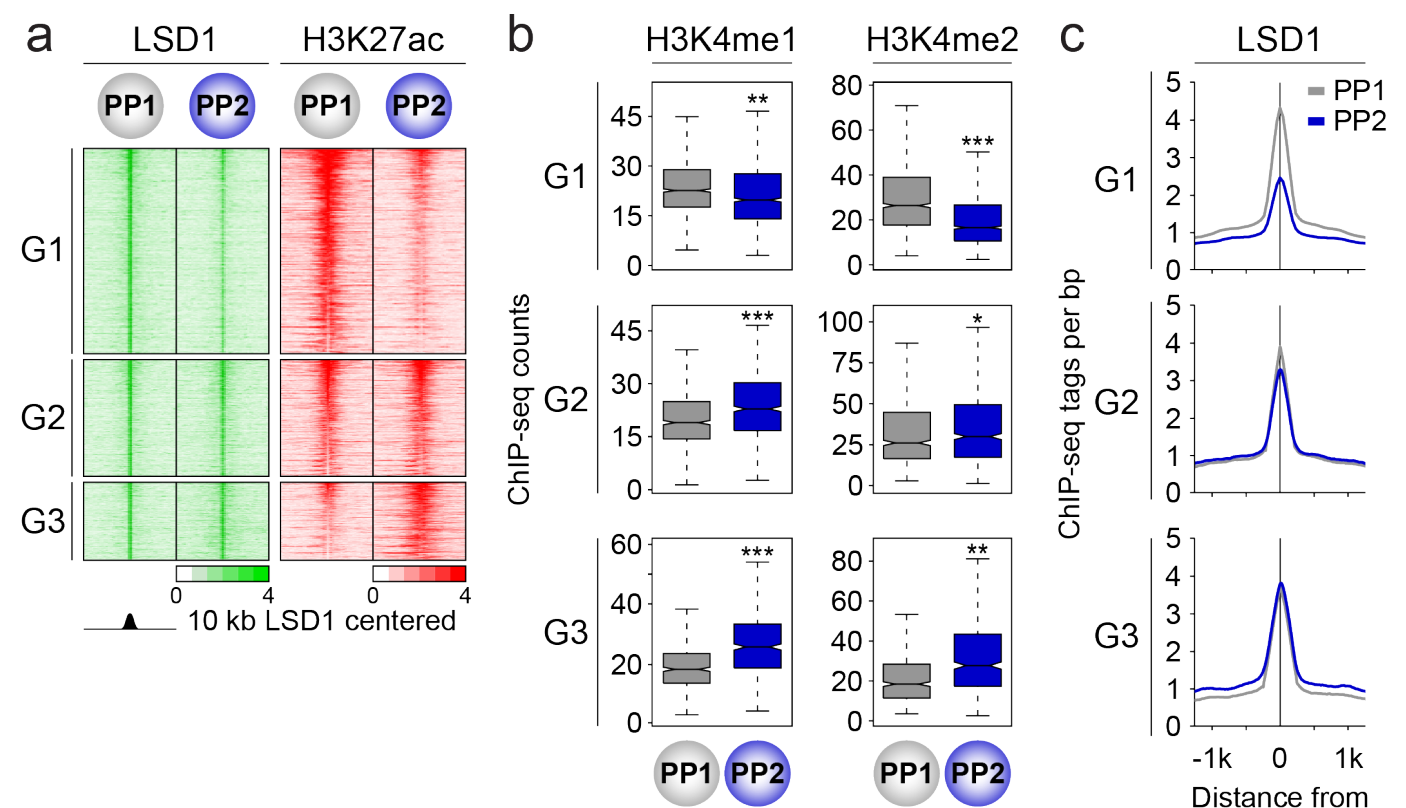

d

H3K27ac
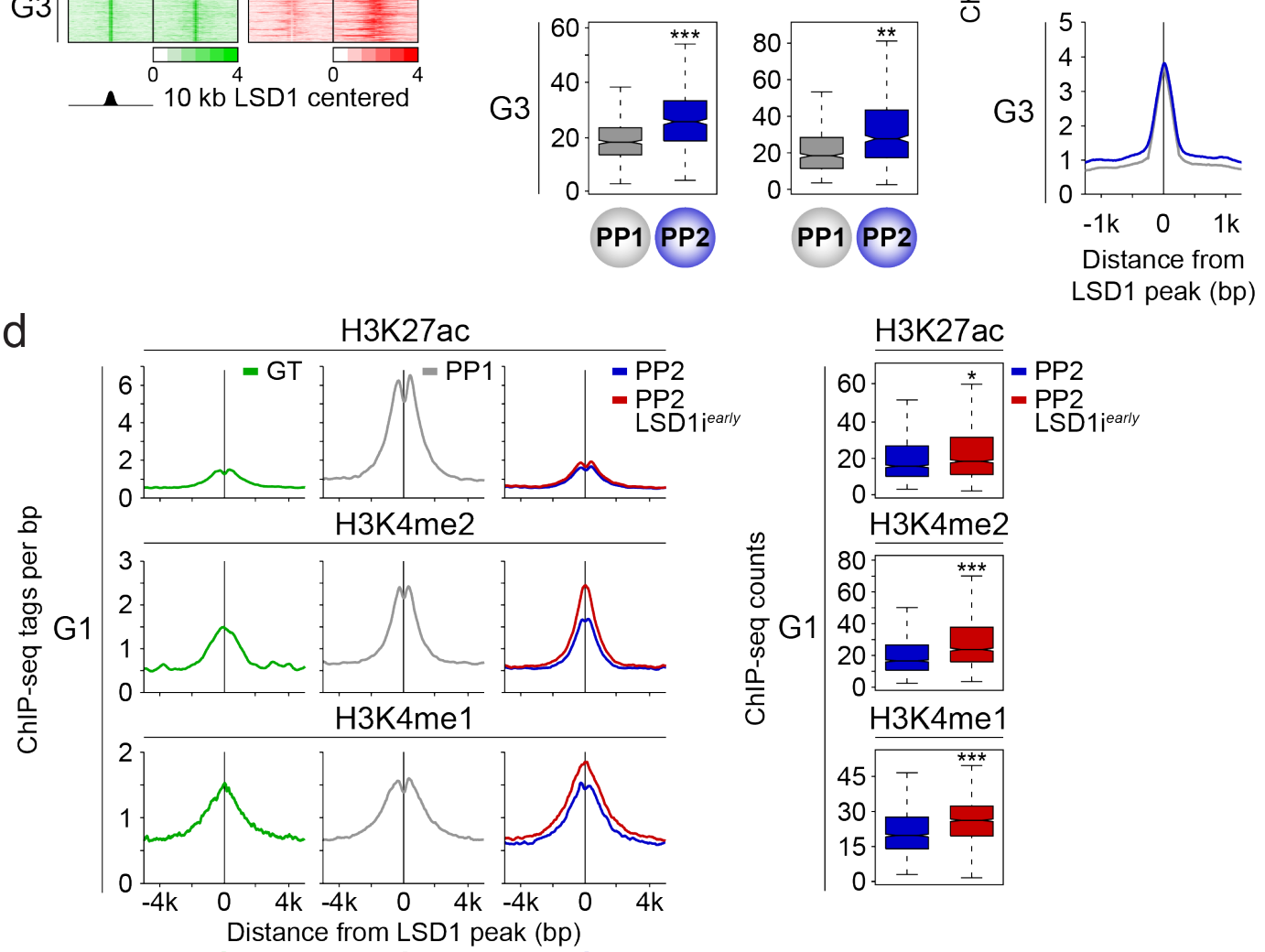

GT

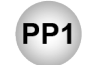

PP2

e

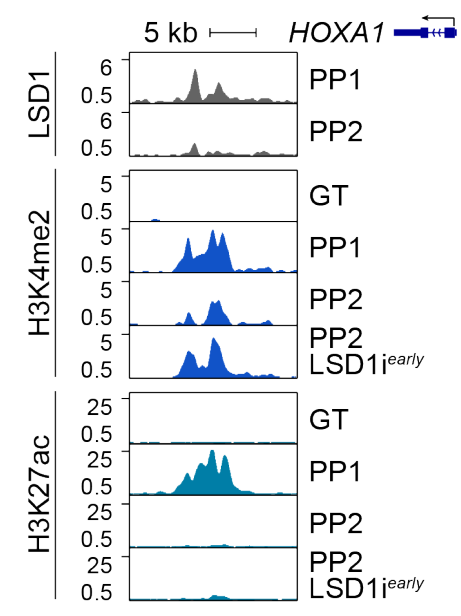

f

$\stackrel{\text { RA, KC, Noggin }}{\longrightarrow}$ PP1 $\stackrel{\text { KGF, EGF }}{\longrightarrow}$ PP2

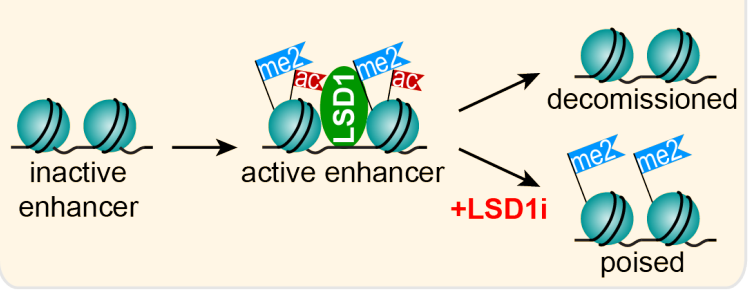


Figure 2. LSD1 inhibition prevents decommissioning of transiently active early pancreatic enhancers. a, Heatmap showing density of ChIP-seq reads for LSD1 and H3K27ac centred on LSD1 peaks, spanning $10 \mathrm{~kb} . \mathrm{G} 1, \mathrm{G} 2$ and G3 groups of LSD1-bound enhancers are deactivated (G1; $n=1345)$, remain active $(G 2 ; n=765)$, or are activated (G3; $n=511$ from PP1 to PP2. $\mathbf{b}$, Box plots of H3K4me1 and H3K4me2 ChIP-seq counts at G1, G2 and G3 enhancers at PP1 and PP2 stages. ${ }^{*} p<0.05 ;{ }^{* *} p<5 e-12 ;{ }^{* * *} p<2.2 e-16$, Wilcoxon rank-sum test. c, Tag density plots displaying LSD1 tag distribution at G1, G2 and G3 enhancers at PP1 and PP2 stages, centred on PP1 LSD1 peaks. d, Tag density plots (left) for G1 enhancers displaying H3K27ac, H3K4me2 and H3K4me1 tag distribution at GT and PP1 stages, and at PP2 stage with and without early LSD1 inhibition (LSD1i ${ }^{\text {early }}$ ). Plots are centred on PP1 LSD1 peaks. Box plots (right) of H3K27ac, H3K4me2, and H3K4me1 ChIP-seq counts at G1 enhancers at PP2 stage with and without early LSD1 inhibition (LSD1 $\left.i^{e a r l y}\right) .{ }^{*} p<0.05 ;{ }^{* * *} p<2.2 e-16$, Wilcoxon rank-sum test. e, LSD1, H3K4me2, and H3K27ac ChIP-seq profiles at an enhancer near HOXA1. f, Model for LSD1dependent enhancer decommissioning. Enhancer deactivation by removal of acetylation from H3K27 occurs independent of LSD1 activity. LSD1 subsequently mediates enhancer decommissioning by removal of $\mathrm{H} 3 \mathrm{~K} 4 \mathrm{me} 2$ marks. KC, KAAD-cyclopamine; KGF, keratinocyte growth factor; RA, retinoic acid; EGF, epidermal growth factor. GT, primitive gut tube; PP1, early pancreatic progenitors; PP2, late pancreatic progenitors. 
a

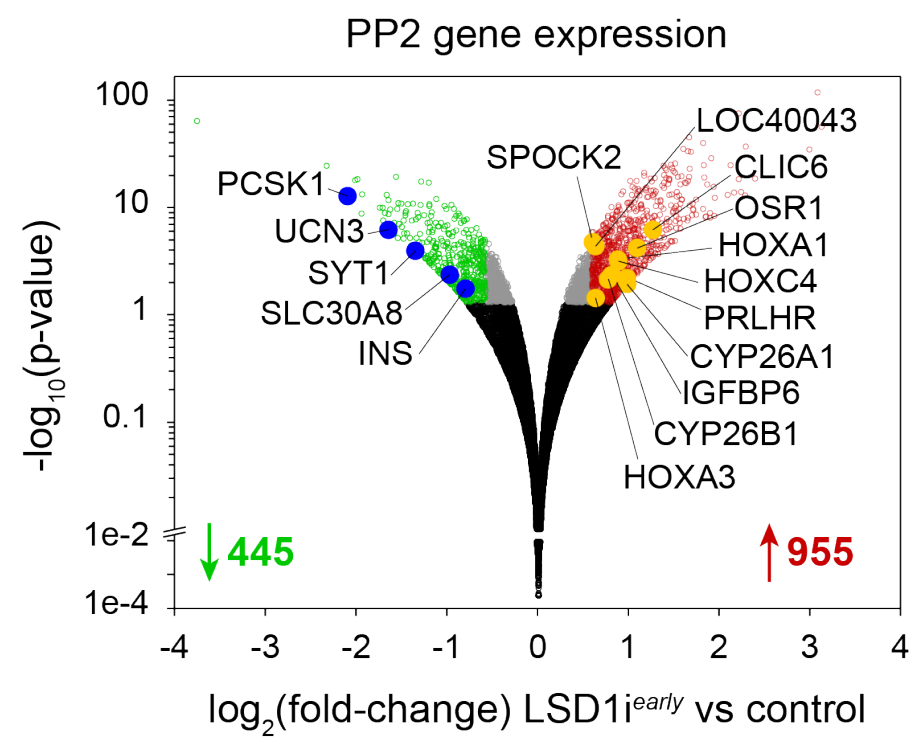

b Enrichment of LSD1-bound regions for LSD1 iearly up-regulated genes

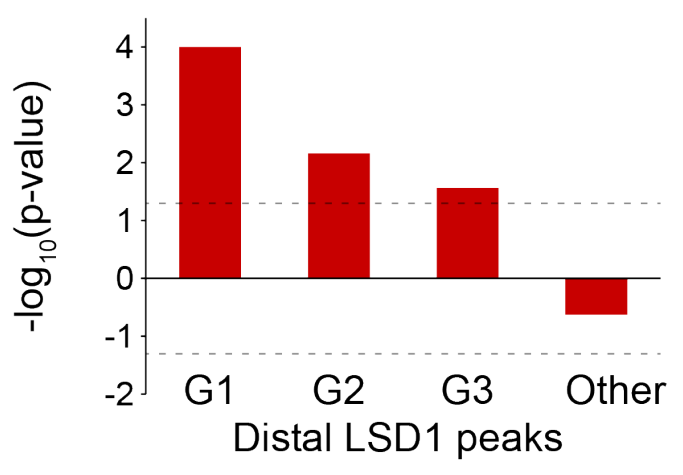

C Proportion of up-regulated genes near enhancers

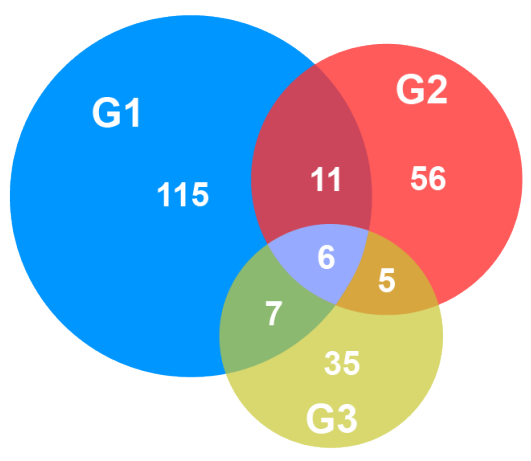

d
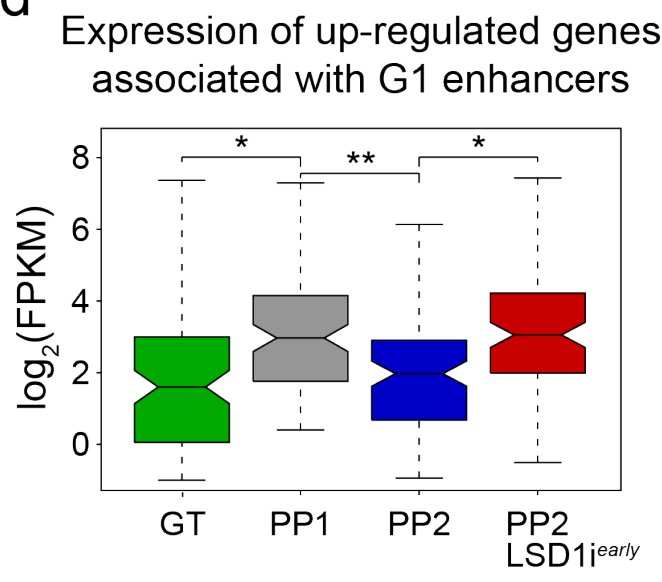

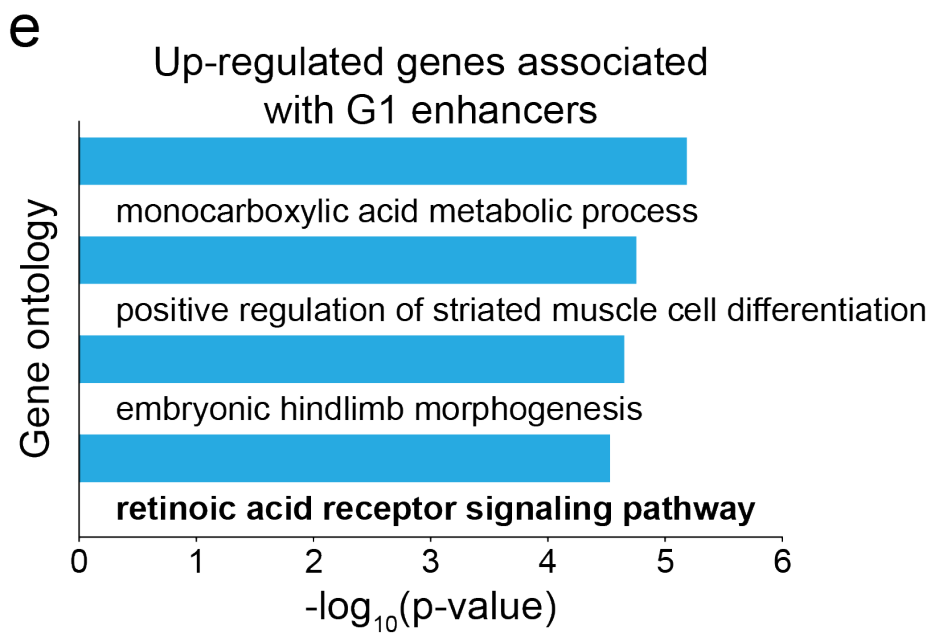


Figure 3. LSD1 activity is necessary for repressing transiently expressed retinoic aciddependent genes. a, Volcano plot of differentially expressed genes at PP2 after LSD1 inhibition from PP1 to PP2 (LSD1i $\left.{ }^{\text {early }}\right)$. Differential expression calculated with DESeq2 and genes with $\geq$ 1.5-fold change up or down. Adjusted p-values of $<0.05$ were considered differentially expressed. 445 genes were down-regulated and 955 were up-regulated in LSD1i ${ }^{\text {early }}$ cultures. Black dots indicate genes not significantly changed ( $p$-value $>0.05$ ), grey dots genes significantly changed ( $p$-value $<0.05$ ) but less than 1.5-fold compared to control, red and green dots genes significantly up- and down-regulated ( $p$-value $<0.05$ and $\geq 1.5$-fold change), respectively ( $n=2$ biological replicates). b, Enrichment analysis of genes up-regulated by LSD1i $\mathrm{i}^{\text {early }}$ within $100 \mathrm{~kb}$ of G1, G2 and G3 or other distal LSD1 peaks. Dashed lines indicate $p$-value $=0.05$ for enrichment (positive value) or depletion (negative value), permutation test. c, Percentage of LSD1 ${ }^{\text {early }}$ up-regulated genes near G1 ( $n=139), G 2(n=78)$ and G3 $(n=53)$ enhancers (within 100kb). d, Box plot of mRNA levels for 139 LSD1i ${ }^{\text {early }}$ up-regulated genes near G1 enhancers. ${ }^{*} p<5 e-6$; ${ }^{* *} p<3 e-7$, Wilcoxon rank-sum test. e, Gene ontology analysis for 139 LSD1i $\mathrm{i}^{\text {early }}$ up-regulated genes near G1 enhancers. GT, primitive gut tube; PP1, early pancreatic progenitors; PP2, late pancreatic progenitors. 
a

Binding motifs enriched at $\mathrm{G} 1$ enhancers versus $\mathrm{G} 2$ and $\mathrm{G} 3$

\begin{tabular}{|c|c|c|}
\hline TF name & Binding motif & $\mathrm{p}$-value \\
\hline RAR/RXR & AGGTCA & $1 \times 10^{-8}$ \\
\hline YY1 & CAAGATGCCGCC & $1 \times 10^{-5}$ \\
\hline E2A & 술ㄷCCTGCA & $1 \times 10^{-4}$ \\
\hline
\end{tabular}

C

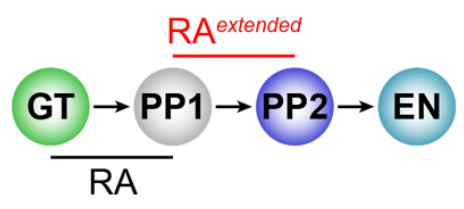

d
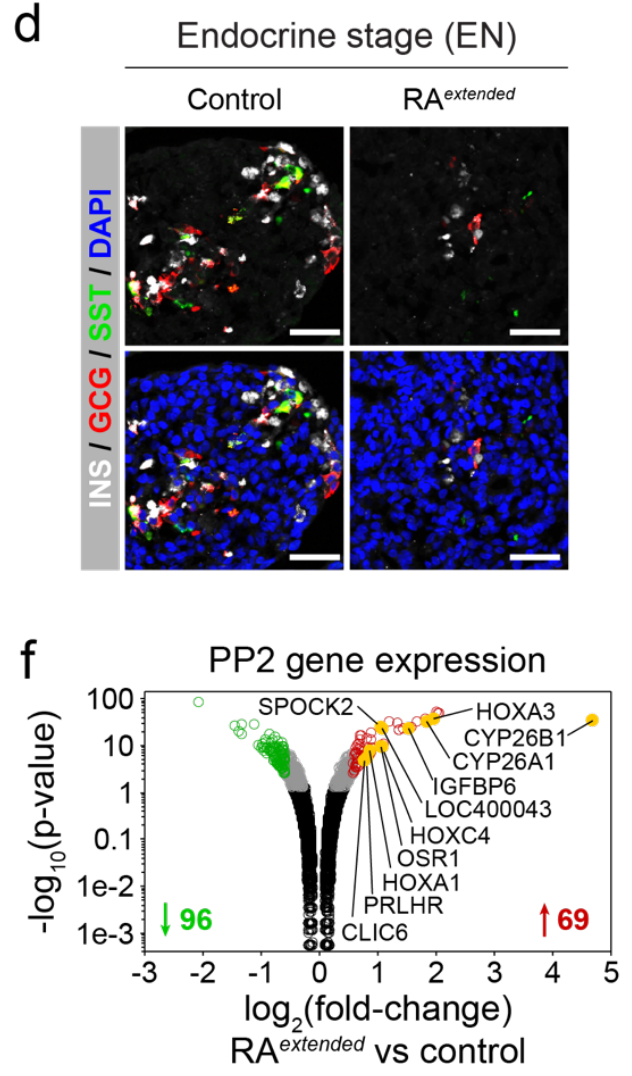

$\mathrm{h}$
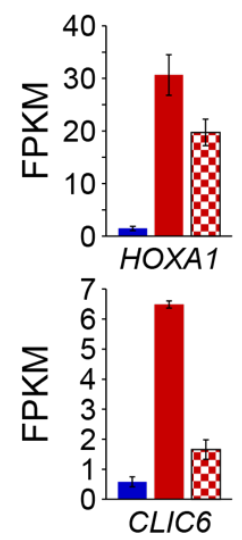

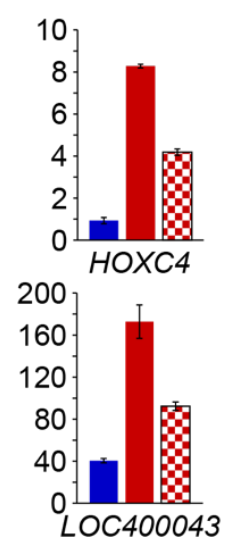

b

G1 enhancers co-bound by RXR

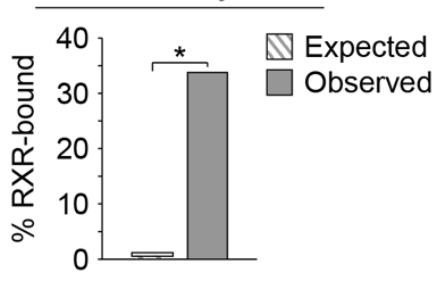

e

\begin{tabular}{cc}
\multicolumn{2}{c}{ Endocrine stage $(\mathrm{EN})$} \\
\hline -antibody & - isotype \\
Control & RA extended
\end{tabular}

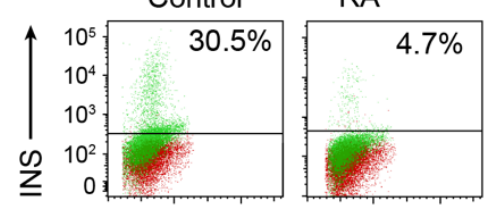

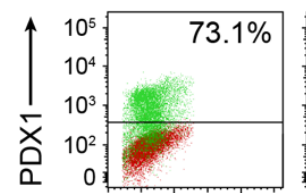

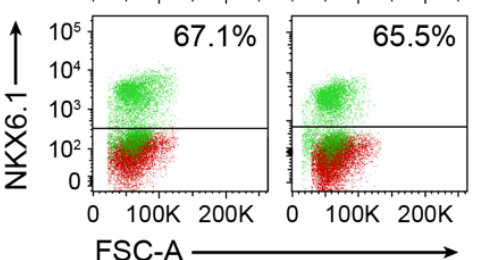

g Enrichment of LSD1-regulated genes among genes up in RA Retended $^{\text {ex }}$

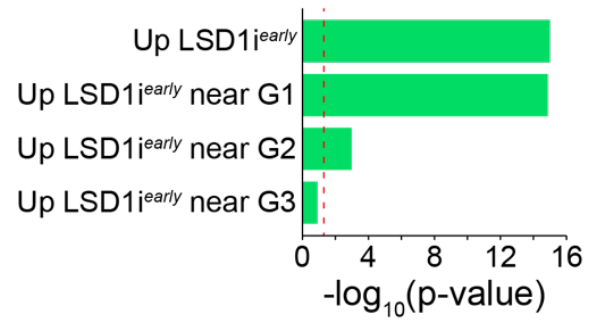

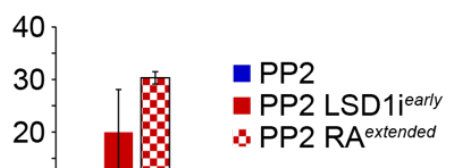

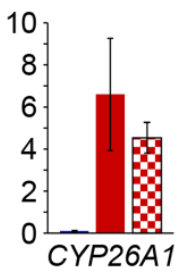

- PP2 LSD1iearly 10

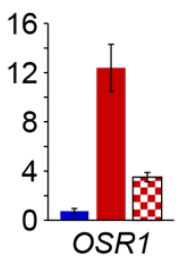

$0 \frac{2}{\text { CYP26B1 }}$
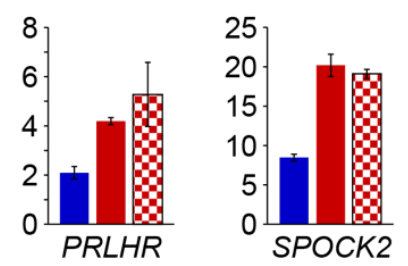
Figure 4. Prolonged retinoic acid exposure of early pancreatic progenitor cells phenocopies LSD1 inhibition. a, Enriched transcription factor (TF) binding motifs with associated p-values for G1 enhancers compared to $G 2$ and G3 enhancers. b. Enrichment for RXR binding among G1 enhancers (within $2 \mathrm{~kb}$ ) versus random genomic regions. * $\mathrm{p}=0$, permutation test. c, Experimental plan to extend retinoic acid (RA) exposure through PP1 to PP2 $\left(\mathrm{RA}^{\text {extended }}\right)$ during hESC differentiation to the endocrine cell stage (EN). d, Immunofluorescent staining for insulin (INS), glucagon (GCG) and somatostatin (SST) in control EN cells compared to EN cells with extended RA treatment $\left(R^{\text {extended }}\right)$. Scale bar, $50 \mu \mathrm{m}$. e, Flow cytometry analysis at EN stage for NKX6.1, PDX1 and INS comparing control and RA ${ }^{\text {extended }}$ cultures. Isotype control for each antibody is shown in red and target protein staining in green. Percentage of cells expressing each protein is indicated (representative experiment, $n=2$ ). $\mathbf{f}$, Volcano plot of differentially expressed genes at PP2 in RA ${ }^{\text {extended }}$ cultures. Differential expression calculated with DESeq2 and genes with $\geq 1.5$-fold change up or down. Adjusted $p$-values $<0.05$ were considered differentially expressed. 96 genes were down-regulated and 69 were up-regulated in RA ${ }^{\text {extended }}$ cultures. Black dots indicate genes not significantly changed ( $p$-value $>0.05$ ), grey dots genes significantly changed ( $p$-value $<0.05$ ) but less than 1.5 -fold compared to control, red and green dots genes significantly up- and down-regulated ( $p$-value $<0.05$ and $\geq 1.5$-fold change), respectively. Yellow dots highlight genes also up-regulated after LSD1 inhibition from PP1 to PP2 $\left(\right.$ LSD1 $\left.^{\text {early }}\right)$ ( $n=2$ biological replicates). $\mathbf{g}$, Enrichment analysis of genes associated with LSD1bound enhancers and up-regulated by LSD1 $\mathrm{i}^{\text {early }}$ among those up-regulated by RA ${ }^{\text {extended }}$. Dashed line indicates $p$-value $=0.05$, Fisher's exact test. $\mathbf{h}$, Relative normalised mRNA levels of select

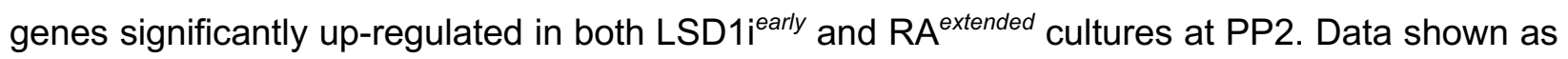
mean FPKM \pm S.E.M. ( $n=2$ biological replicates). GT, primitive gut tube; PP1, early pancreatic progenitors; PP2, late pancreatic progenitors. 
a

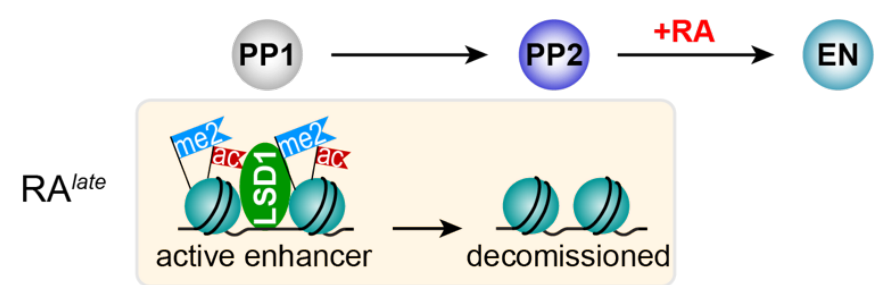

LSD1iearly + RA $^{\text {late }}$

active enhancer

decomissioned

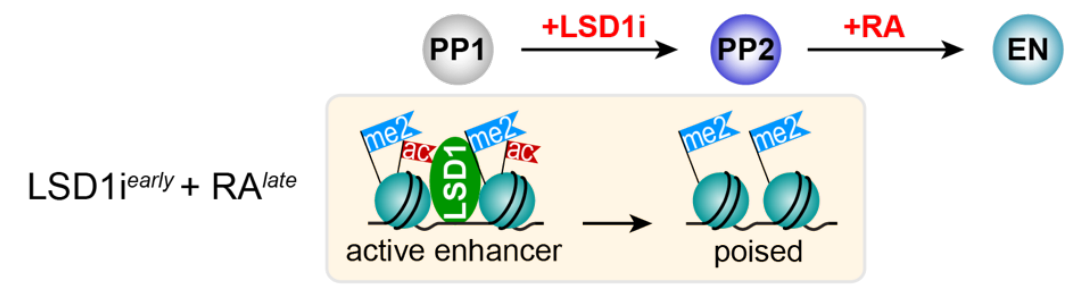

b

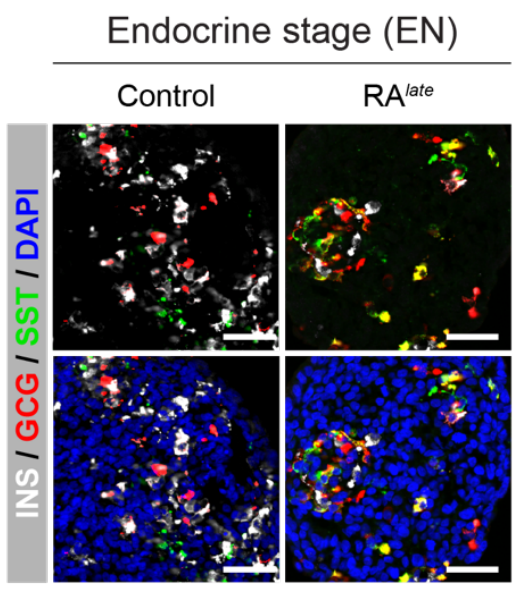

C

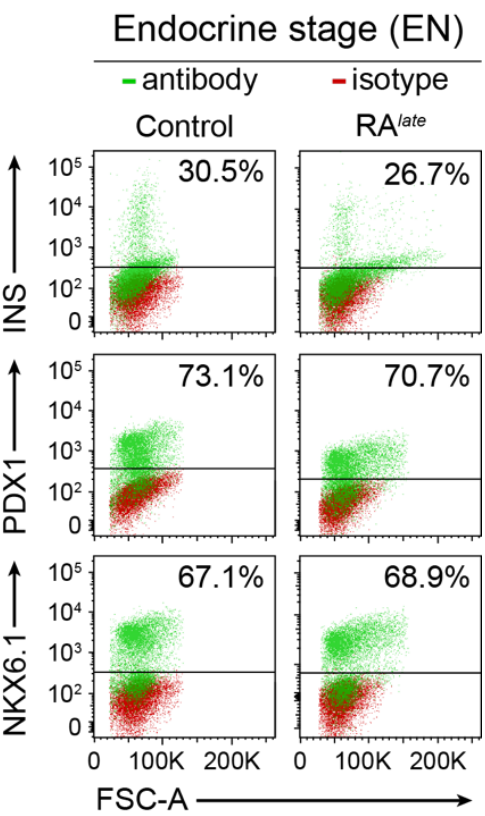

d

Endocrine stage (EN)

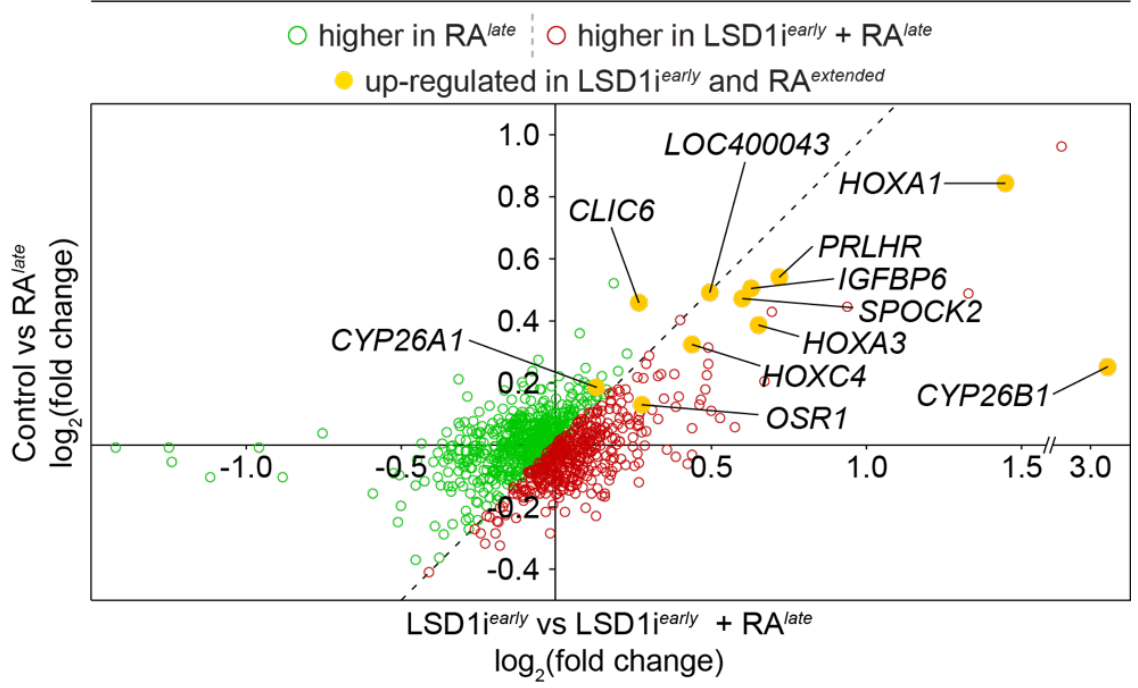


Figure 5. LSD1 decreases future inducibility of RA-dependent genes by retinoic acid. a, Experimental plan to re-introduce retinoic acid (RA) during the PP2 to endocrine (EN) transition of hESC differentiation without $\left(\mathrm{RA}^{\text {late }}\right)$ and with prior inhibition of LSD1 (LSD1i early $\left.+\mathrm{RA}^{\text {late }}\right)$. The cartoon depicts the chromatin state as determined in Figure 2. b, Immunofluorescent staining for insulin (INS), glucagon (GCG) and somatostatin (SST) in control EN cells compared to EN cells with late $\mathrm{RA}$ treatment $\left(\mathrm{RA}^{\text {late }}\right)$. Scale bar, $50 \mu \mathrm{m}$. c, Flow cytometry analysis at EN stage for NKX6.1, PDX1 and INS comparing control and RA ${ }^{\text {late }}$ cells. Isotype control for each antibody is shown in red and target protein staining in green. Percentage of cells expressing each protein is indicated (representative experiment, $n=2$ ). $\mathbf{d}$, Gene expression changes in $R A^{\text {late }}$ vs control EN cells compared to gene expression changes in LSD1i ${ }^{\text {early }}+\mathrm{RA}^{\text {late }}$ vs LSD1i ${ }^{\text {early }}$ EN cells. Green dots indicate genes more increased in $\mathrm{RA}^{\text {late }}$ and red dots indicate genes more increased in $\mathrm{LSD}_{1} \mathrm{i}^{\text {early }}+\mathrm{RA}^{\text {late }}$ compared to respective controls. Yellow dots highlight genes up-regulated after both LSD1 ${ }^{\text {early }}$ and extended RA treatment $\left(\mathrm{RA}^{\text {extended }}\right)$ from PP1 to PP2. ( $\mathrm{n}=2$ biological replicates per condition). PP1, early pancreatic progenitors; PP2, late pancreatic progenitors; FSC-A, forward scatter area. 
a
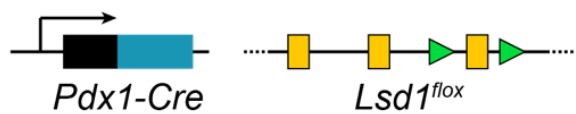

b

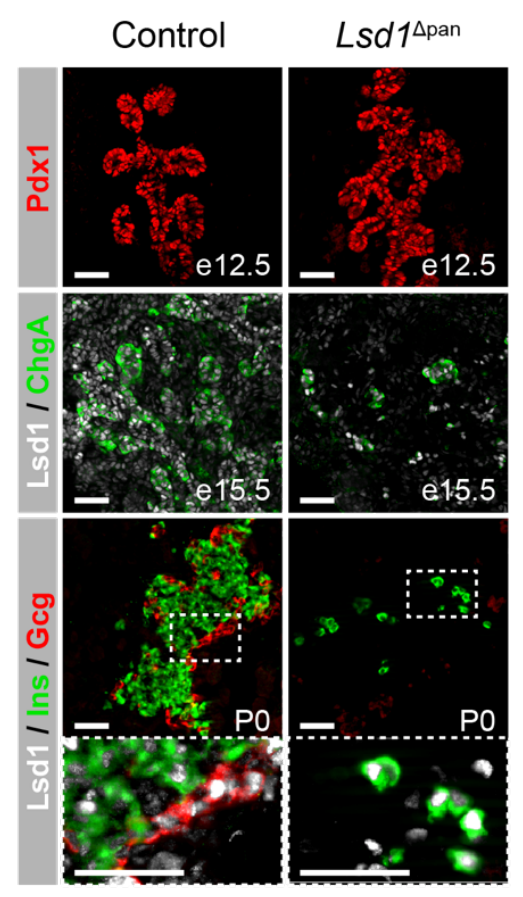

e

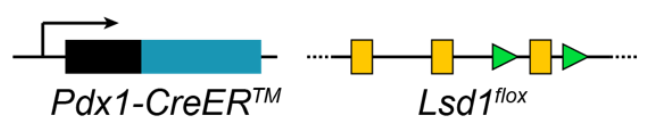

f

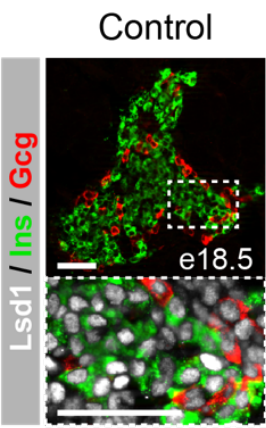

Pdx1 expression

(e9.5)

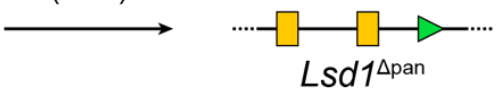

C

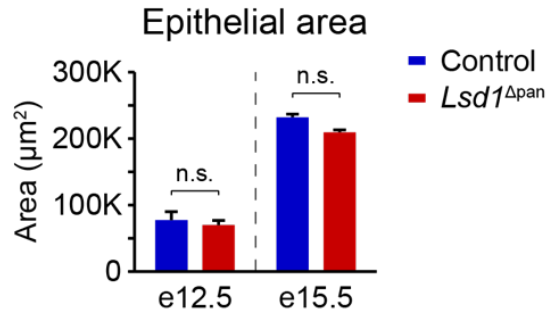

d

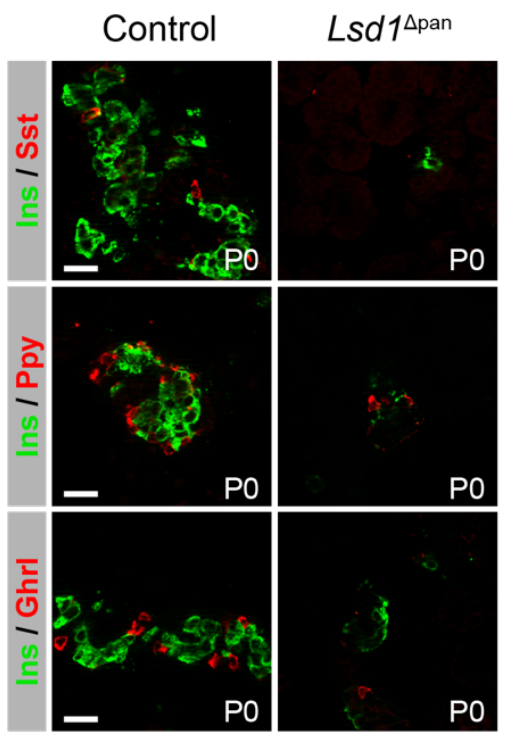

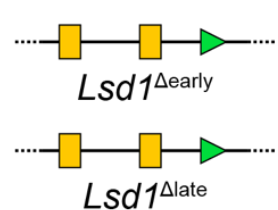

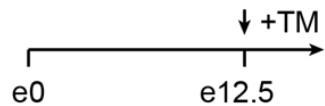

Lsd14late
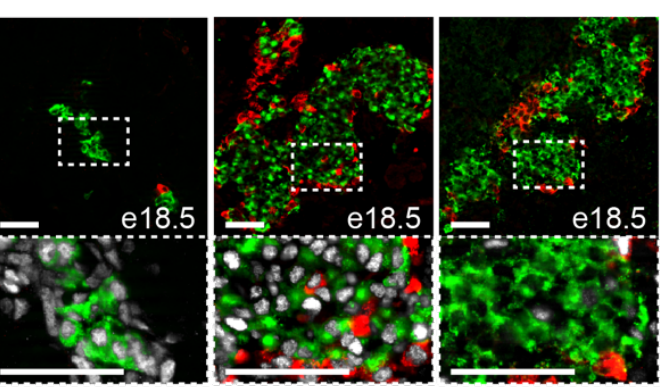
Figure 6. Lsd1 is required for endocrine cell formation in mice during a short window in early pancreatic development. a, Strategy for conditional $L s d 1$ deletion in embryonic pancreatic progenitors of mice (Lsd1 $1^{\Delta \text { pan }}$ mice). Yellow boxes: exons; green triangles: loxP sites. b, Immunofluorescent staining for Pdx1 at embryonic day (e) 12.5, Lsd1 and chromogranin A (ChgA) at e15.5, and Lsd1, insulin (Ins) and glucagon (Gcg) at postnatal day $(\mathrm{P}) 0$ in control and $L s d 1^{\Delta \text { pan }}$ mice. Boxed areas are shown in higher magnification. Scale bar, $50 \mu \mathrm{m}$. c, Quantification of pancreatic epithelial area at e12.5 and e15.5, as means \pm S.E.M. $(n=3$ per genotype $)$. n.s. $=p>$ 0.05 , Student's t-test. d, Immunofluorescent staining for Ins with somatostatin (Sst), pancreatic polypeptide (Ppy) and ghrelin (Ghrl) at P0 in control and $L s d 1^{\Delta p a n}$ mice. Scale bar, $25 \mu \mathrm{m}$. e, Strategy for tamoxifen-inducible $L s d 1$ deletion in embryonic pancreatic progenitors of mice at e10.5 (Lsd $\left.1^{\Delta \text { early }}\right)$ and e12.5 (Lsd1 $\left.1^{\Delta \text { late }}\right)$. Yellow boxes: exons; green triangles: loxP sites. f, Immunofluorescent staining for Lsd1, Ins and Gcg at e18.5 in control, $L s d 1^{\Delta \text { early }}$ and $L s d 1^{\Delta l a t e}$ mice. Boxed areas are shown in higher magnification. Scale bar, $50 \mu \mathrm{m}$. 
bioRxiv preprint doi: https://doi.org/10.1101/716647; this version posted August 1, 2019. The copyright holder for this preprint (which was not certified by peer review) is the author/funder. All rights reserved. No reuse allowed without permission.

\section{SUPPLEMENTAL INFORMATION}

Figures S1-S7

Tables S1-S7 
a

hESC differentiation

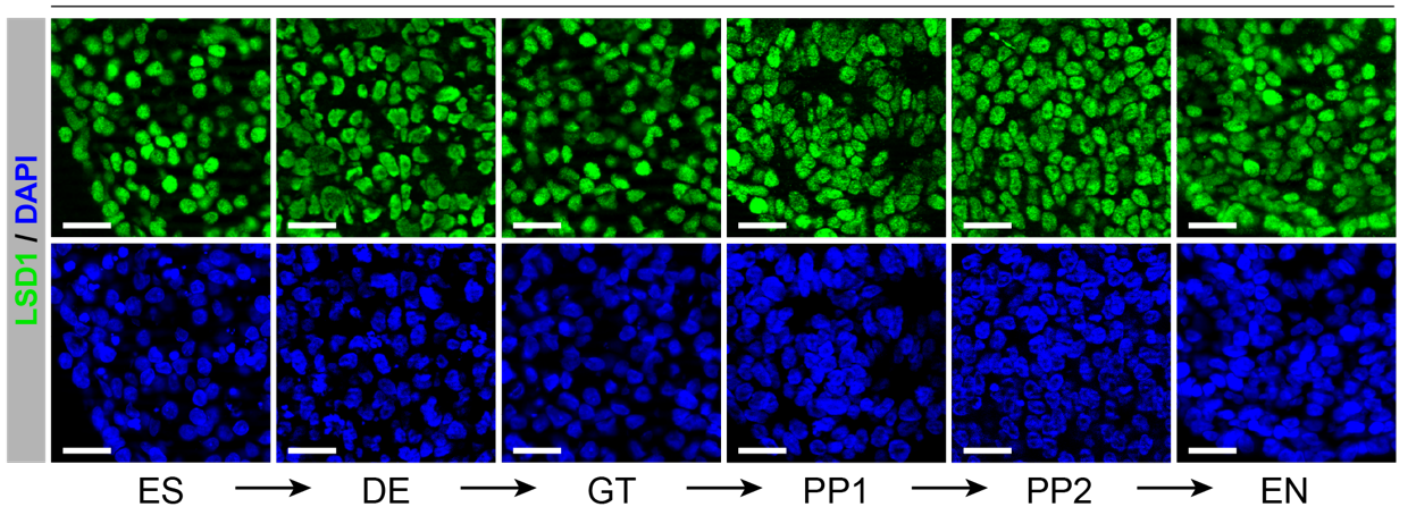

b

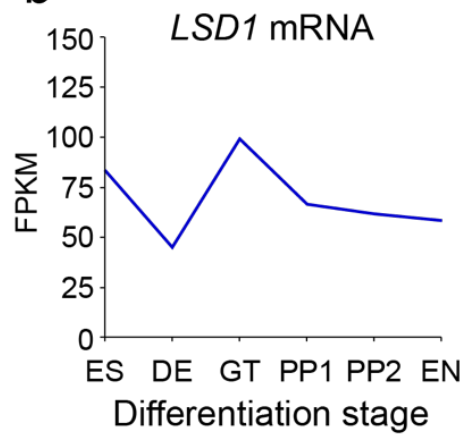

C

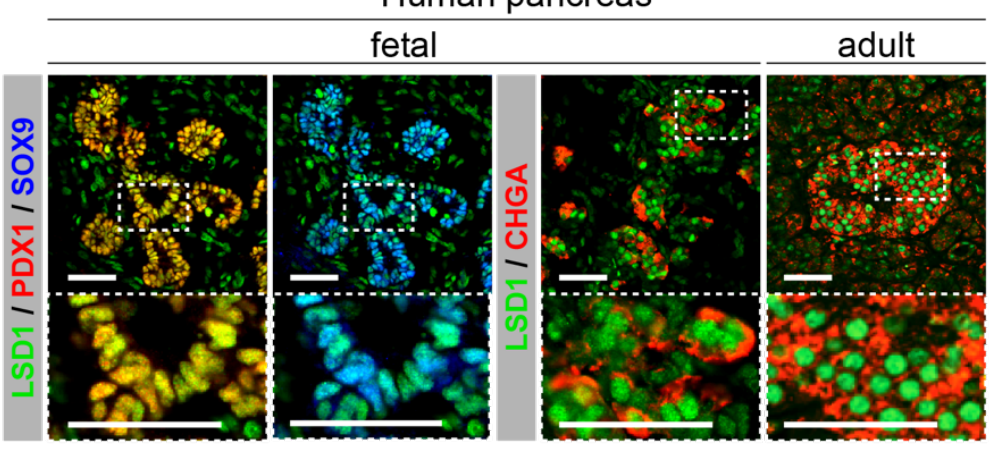

adult

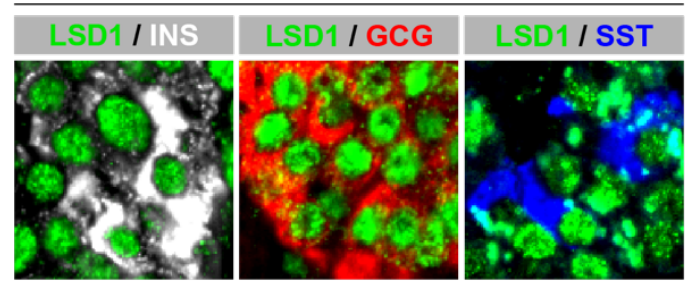

e Late pancreatic progenitors (PP2)

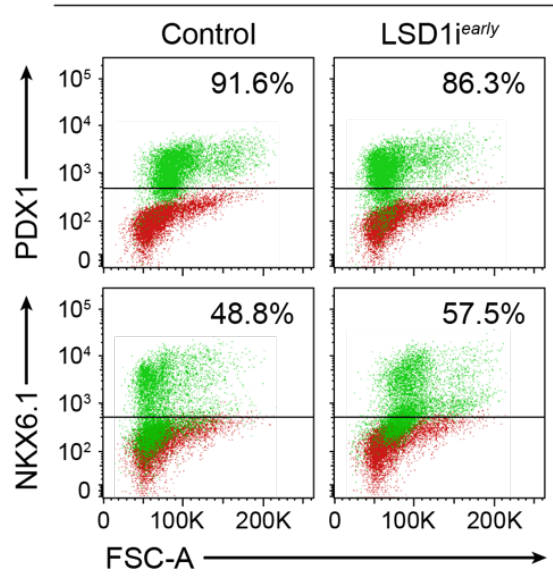




\section{Supplementary Figure 1. Characterisation of LSD1 expression and effects of LSD1} inhibition on pancreatic progenitor cells. a, Immunofluorescent staining for LSD1 at each stage of hESC differentiation. Scale bar, $25 \mu \mathrm{m}$. b, LSD1 mRNA expression at each stage of differentiation determined by RNA-seq, measured in fragments per kilobase per million fragments mapped (FPKM). Values shown as $\log _{2}(F P K M)$. c, Immunofluorescent staining of pancreatic sections for LSD1 with the pancreatic progenitor markers PDX1 and SOX9 (55 days postconception (dpc) foetal pancreas) or the pan-endocrine marker chromogranin A (CHGA) (94 dpc and adult pancreas). Scale bar, $50 \mu \mathrm{m}$ (upper). Immunofluorescent staining for LSD1 with insulin (INS), glucagon (GCG) and somatostatin (SST) in adult human pancreas. Scale bar, $10 \mu \mathrm{m}$ (lower). d, Immunofluorescent staining for NKX6.1 and PDX1 in control and LSD1i ${ }^{\text {early }}$ PP2 cells. Scale bar, $50 \mu \mathrm{m}$. e, Flow cytometry analysis for NKX6.1 and PDX1 comparing control and LSD1i ${ }^{\text {early }}$ PP2 cells. Isotype control for each antibody is shown in red and target protein staining in green. Percentage of cells expressing each protein is indicated (representative experiment, $\mathrm{n}$ =2). S, human embryonic stem cells; DE, definitive endoderm; GT, primitive gut tube; PP1, early pancreatic progenitors; PP2, late pancreatic progenitors; EN, endocrine cell stage; FSC-A, forward scatter area. 
a

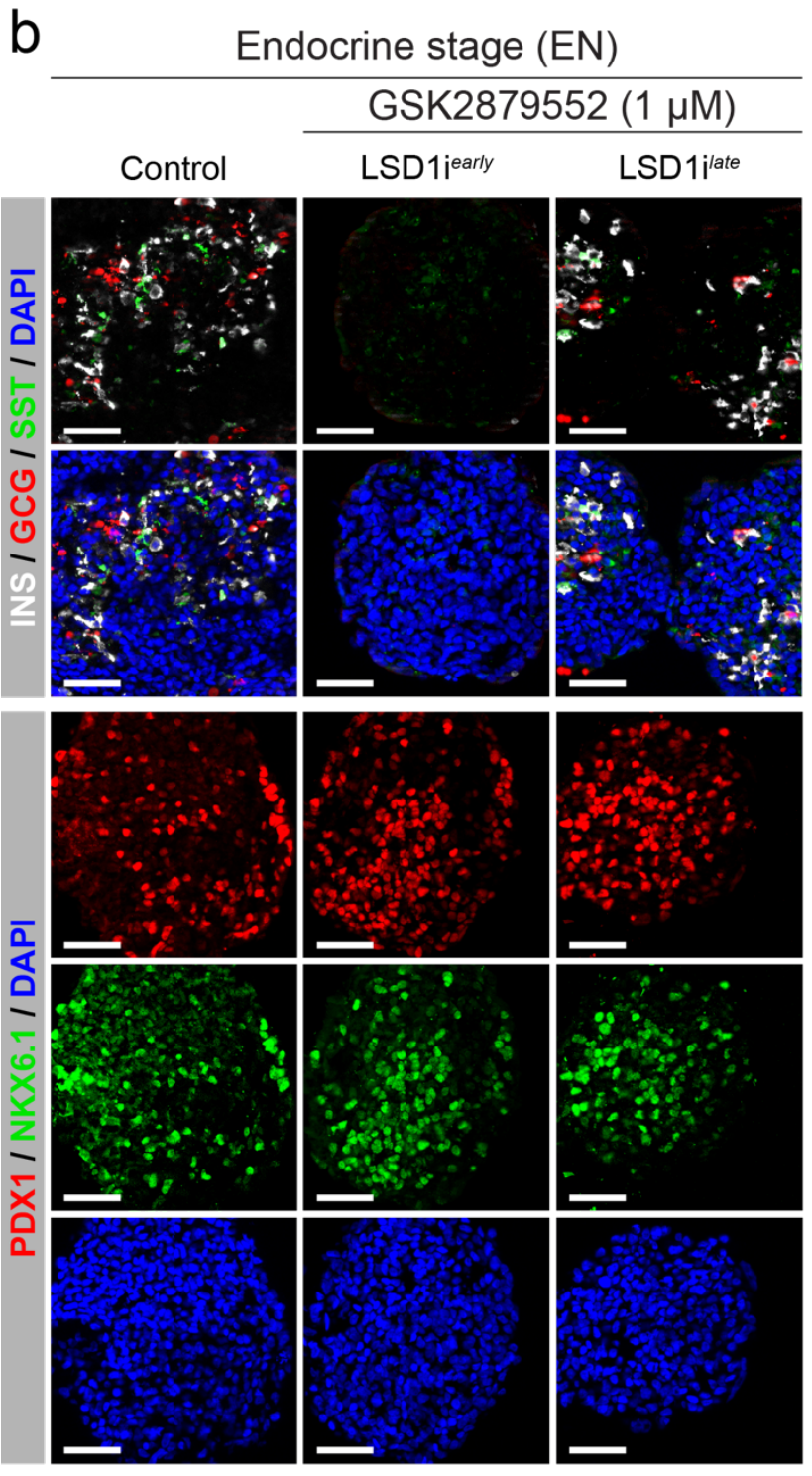

C
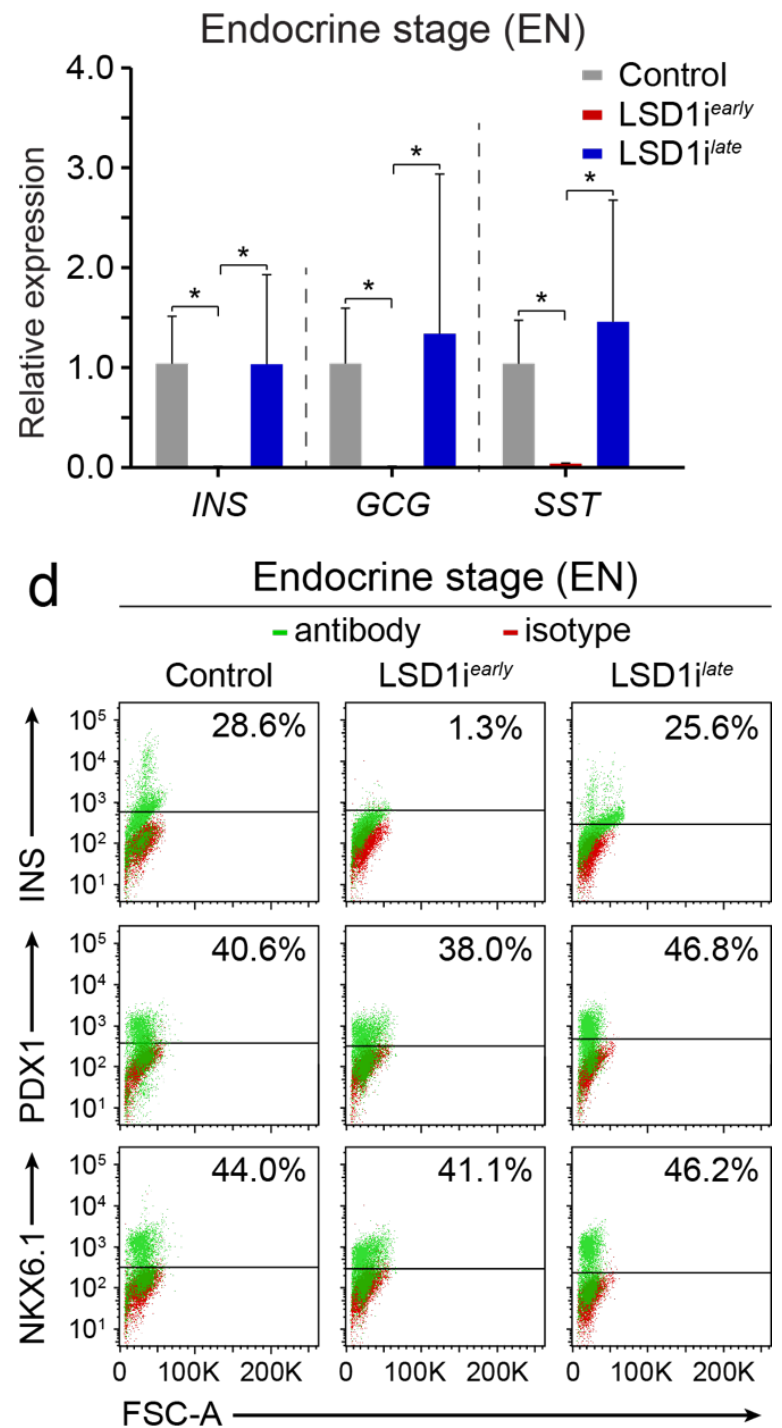


\section{Supplementary Figure 2. Effects of different LSD1 inhibitors on endocrine cell} differentiation. a, Flow cytometry analysis at EN stage for insulin (INS) comparing control cells to cells treated with the LSD1 inhibitors (SP2509 [1uM], GSK-LSD1 [1 $\mu$ M] and GSK2879552 [1 $\mu \mathrm{M}]$ ) during the PP1 to PP2 transition. b, Immunofluorescent staining for pancreatic hormones INS, glucagon (GCG) and somatostatin (SST) or PDX1 and NKX6.1 in control EN cells compared to EN cells with early (LSD1i $\left.{ }^{\text {early }}\right)$ and late (LSD1ilate $)$ LSD1 inhibition mediated by GSK2879552. Scale bar, $50 \mu \mathrm{m}$. c, qRT-PCR analysis for INS, GCG and SST in control, LSD1 $\mathrm{i}^{\text {early }}$ and LSD1ilate EN cells, following GSK2879552-mediated LSD1 inhibition. Data are shown as mean \pm S.E.M. ( $n$ $=2$ biological replicates). ${ }^{*} p<0.05$, Student's t-test. $\mathbf{d}$, Flow cytometry analysis at EN stage for NKX6.1, PDX1 and INS comparing control, LSD1i ${ }^{\text {early }}$ and LSD1ilate cells, following GSK2879552mediated LSD1 inhibition. Isotype control for each antibody is shown in red and target protein staining in green. Percentage of cells expressing each protein is indicated (representative experiment, $n=2$ ). EN, endocrine cell stage; FSC-A, forward scatter area. 
a

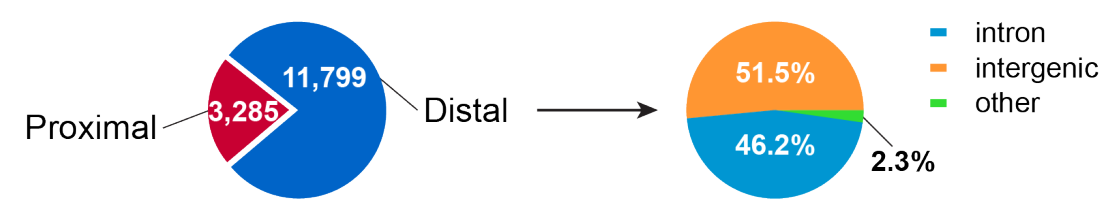

b

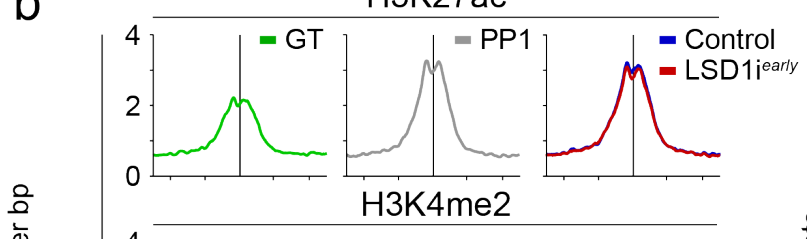

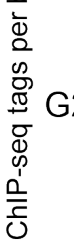

(2)

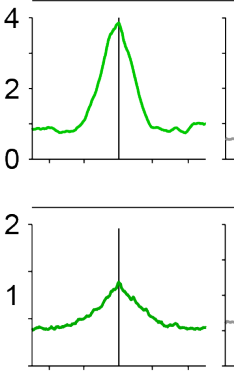

|

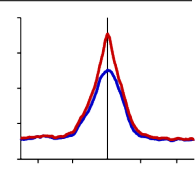

H3K4me1

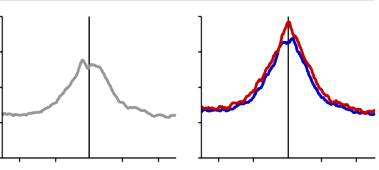

H3K27ac

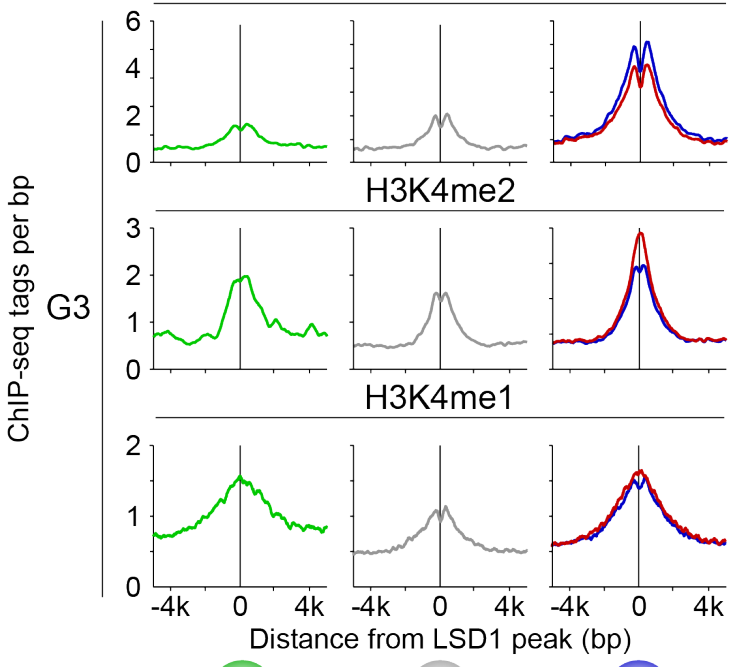

GT

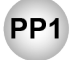

C CYP26A1
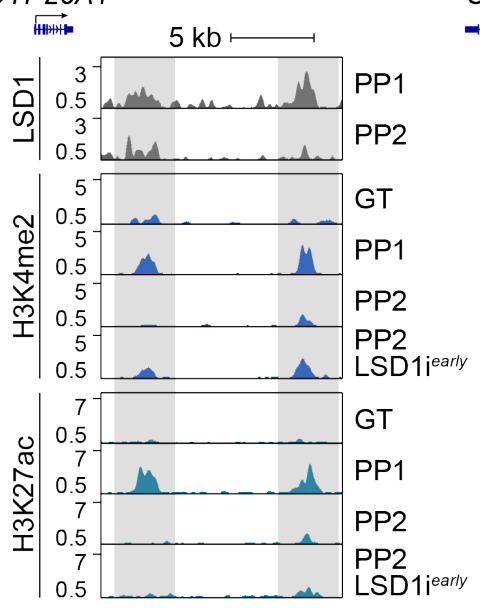

CYP26B1
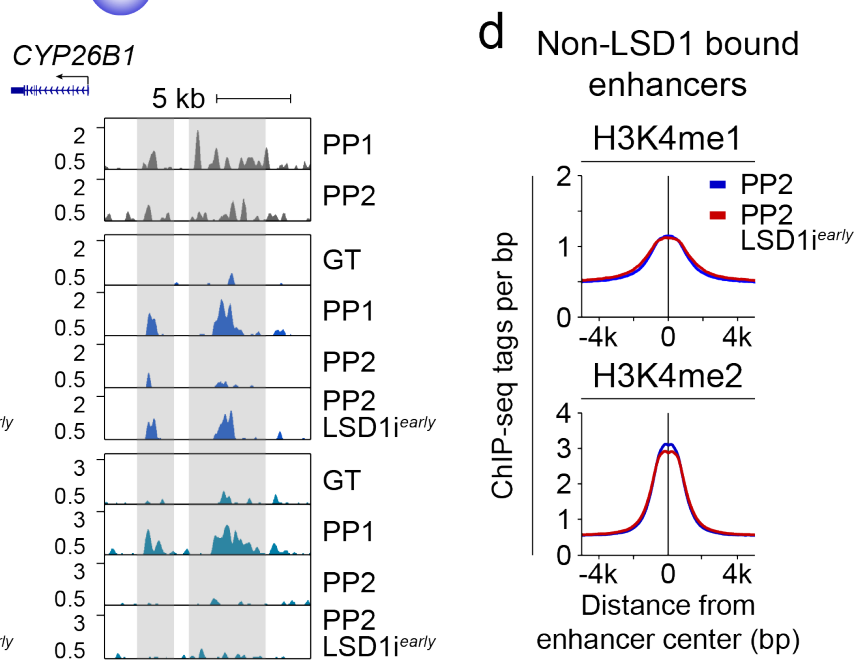


\section{Supplementary Figure 3. Effects of LSD1 inhibition on chromatin state at distal genomics}

regions. a, LSD1 peak localisation across the genome relative to transcriptional start sites (TSSs). 15,084 total LSD1 peaks identified in PP1. 3,285 peaks are proximal (within 3kb of a TSS) and 11,799 distal (> 3kb from a TSS). b, Tag density plots for G2 and G3 enhancers displaying H3K27ac, H3K4me2 and H3K4me1 tag distribution at PP1 and PP2 stage with and without early LSD1 inhibition (LSD1i ${ }^{\text {early }}$, left). Plots are centred on PP1 LSD1 peaks. Box plots of H3K27ac, H3K4me2, and H3K4me1 ChIP-seq counts at G2 and G3 enhancers at PP2 stage with and without early LSD1 inhibition (LSD1iearly, right). ${ }^{*} p<5 e-4 ;{ }^{* *} p<8.5 e-6 ;{ }^{* * *} p<3.5 e-18$, Wilcoxon rank-sum test. c, LSD1, H3K4me2, and H3K27ac ChIP-seq profiles at enhancers near CYP26A1. d, Tag density plots for PP1 enhancers (defined by H3K27ac peaks) not bound by LSD1 displaying H3K4me1 and H3K4me2 tag distribution at PP2 stage with and without early LSD1 inhibition (LSD1i ${ }^{\text {early }}$ ). Plots are centred on PP1 enhancers not bound by LSD1. PP1, early pancreatic progenitors; PP2, late pancreatic progenitors. 
a

\section{Enrichment of LSD1-bound regions for LSD1 ${ }^{\text {early }}$ down-regulated genes}

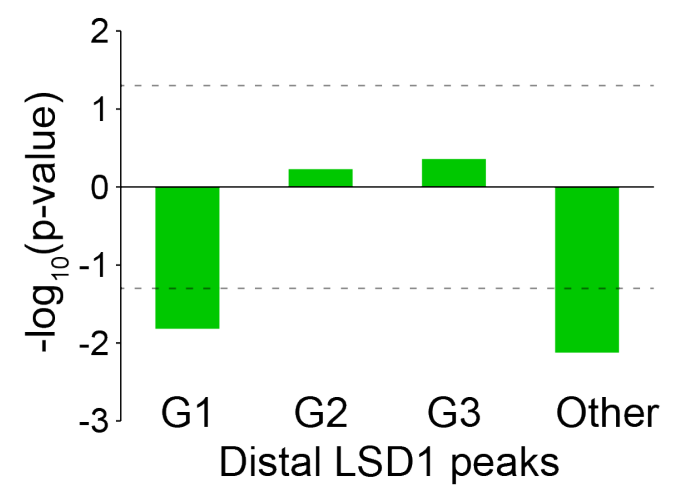

b

Expression of up-regulated genes near $\mathrm{G} 2$ enhancers

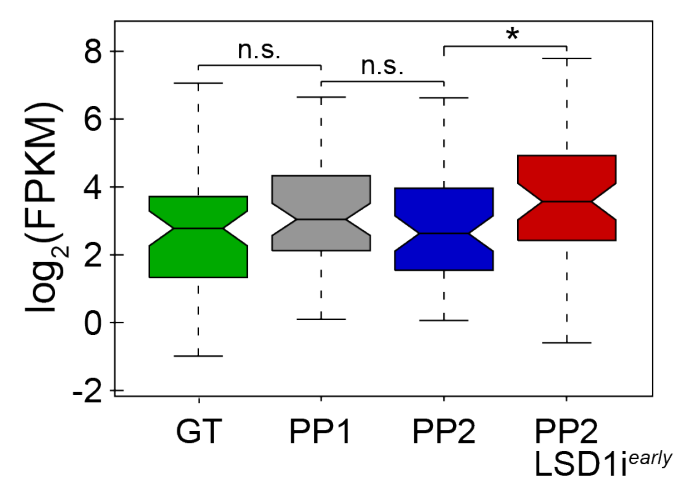

C

Expression of up-regulated genes near G3 enhancers

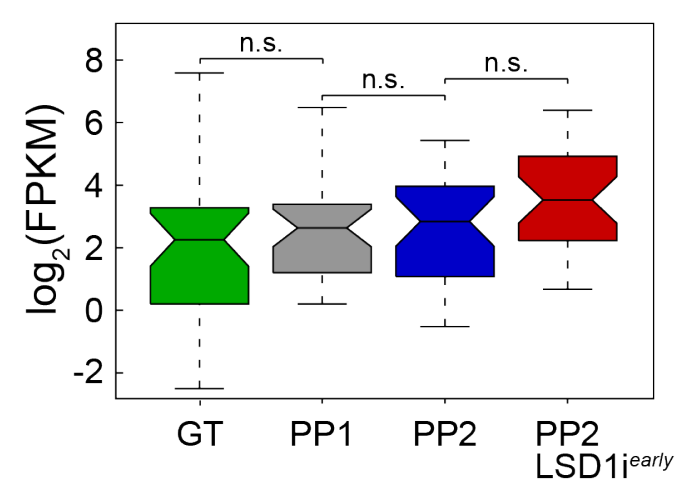

Up-regulated genes near G2 enhancers

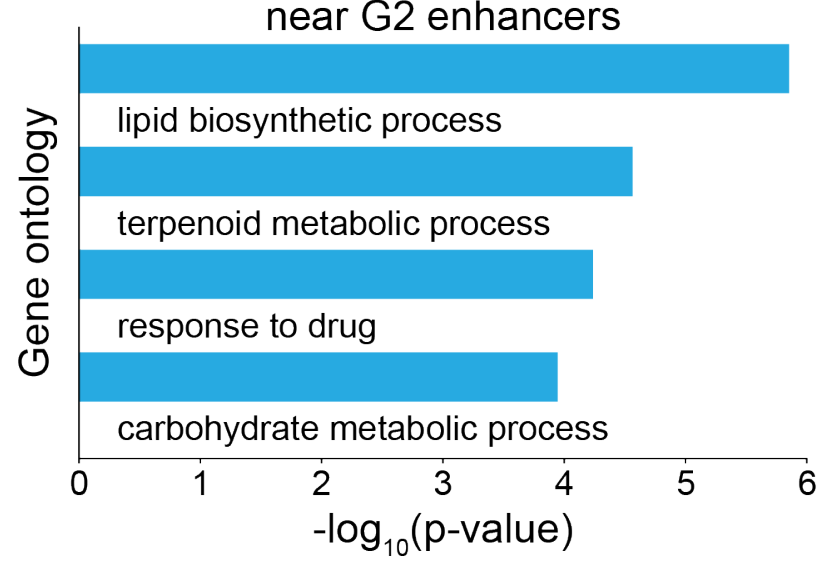

Up-regulated genes near G3 enhancers

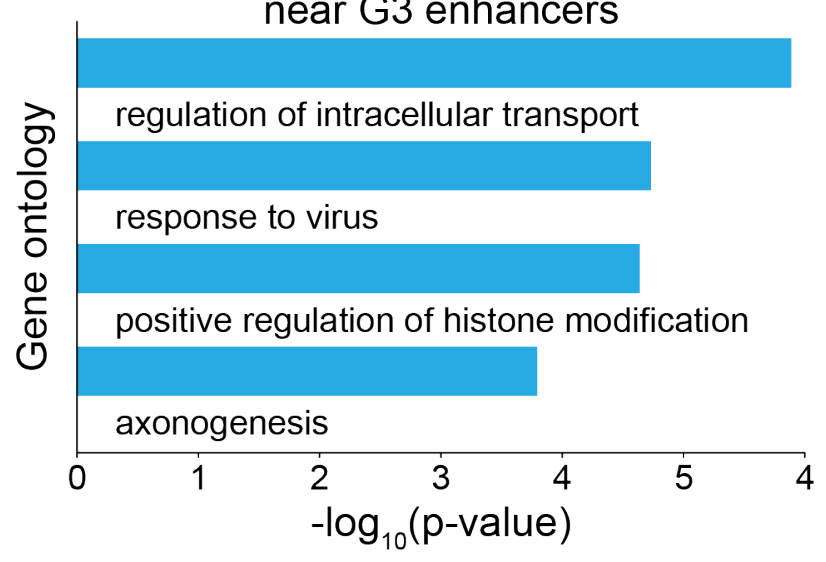




\section{Supplementary Figure 4. Characterisation of genes dysregulated after LSD1 inhibition. a,} Enrichment analysis of genes down-regulated by LSD1 ${ }^{\text {early }}$ within $100 \mathrm{~kb}$ of G1, G2 and G3 or other distal LSD1 peaks. Dashed lines indicate $p$-value $=0.05$ for enrichment (positive value) or depletion (negative value). b, Box plot of mRNA levels for 78 LSD1i ${ }^{\text {early }}$ up-regulated genes associated with G2 enhancers (left) and gene ontology analysis of those genes (right). * $p<0.05$; n.s. $=p>0.05$, Wilcoxon rank-sum test. c, Box plot of mRNA levels for 53 LSD $1 i^{\text {early }}$ up-regulated genes associated with G3 enhancers (left) and gene ontology analysis of those genes (right). n.s. $=p>0.05$, Wilcoxon rank-sum test. 
a

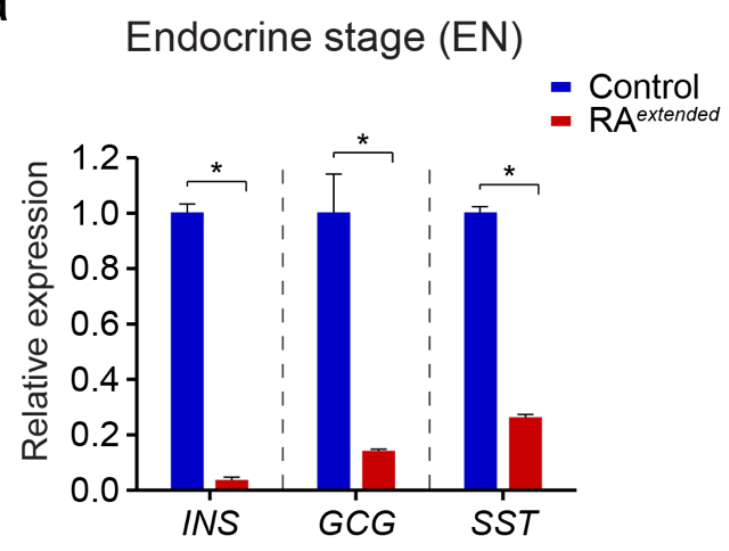

b

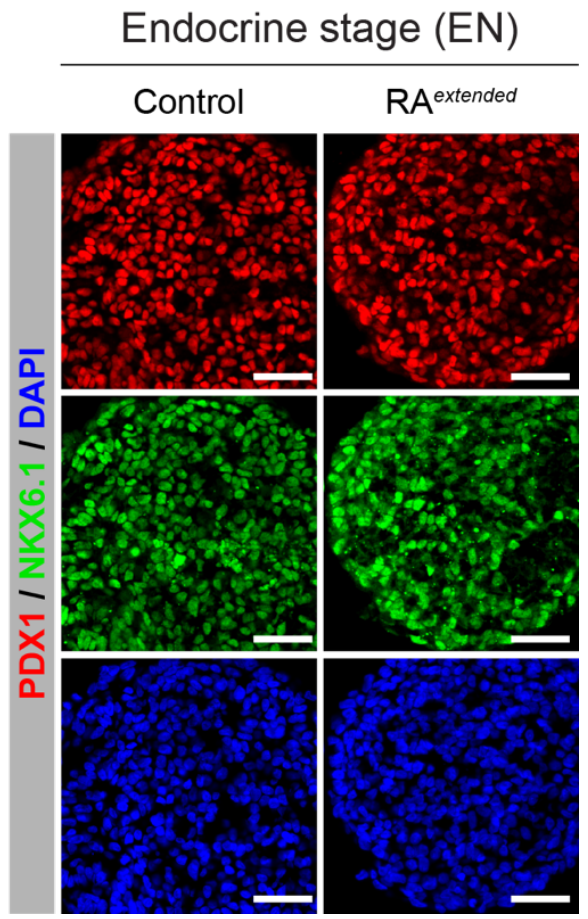

\section{Supplementary Figure 5. Effects of prolonged retinoic acid treatment on pancreatic} progenitor and endocrine cell phenotypes. a, qRT-PCR analysis for insulin (INS), glucagon $(G L U)$ and somatostatin (SST) in control and $\mathrm{RA}^{\text {extended }}$ endocrine stage (EN) cells. Data are shown as mean \pm S.E.M. ( $n=2$ biological replicates). ${ }^{*} p<0.001$, Student's t-test. b, Immunofluorescent staining for PDX1 and NKX6.1 in control EN compared to EN cells with $\mathrm{RA}^{\text {extended }}$ treatment. Scale bar, $50 \mu \mathrm{m}$. 
a

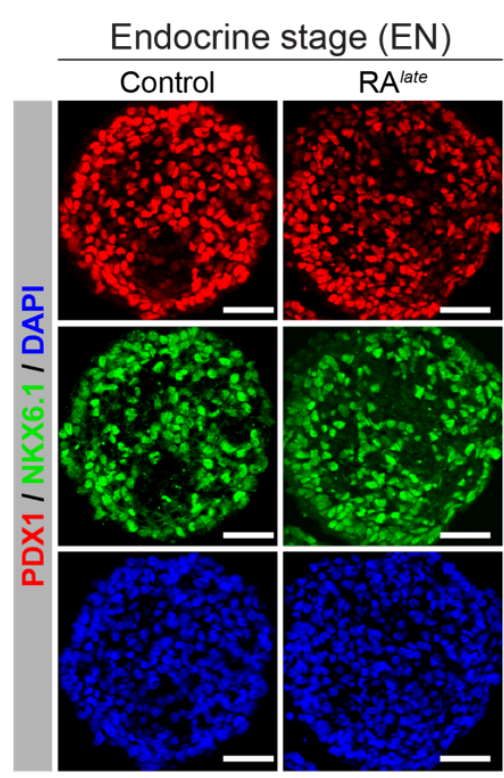

C

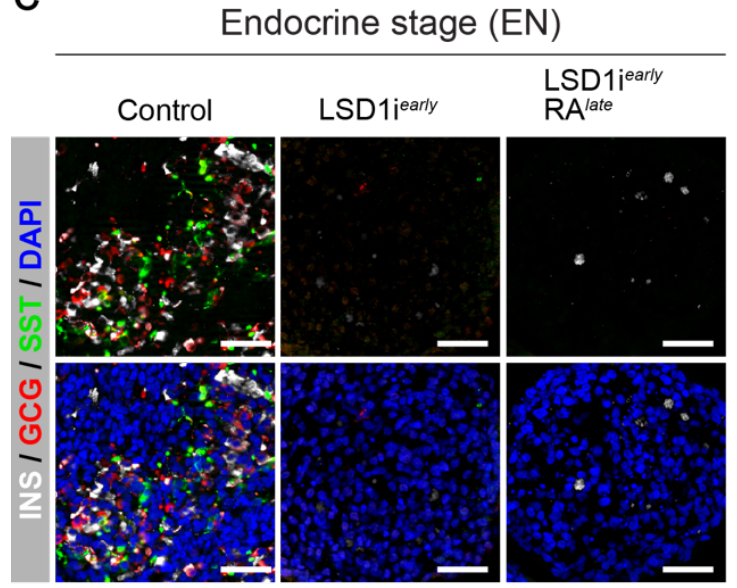

b

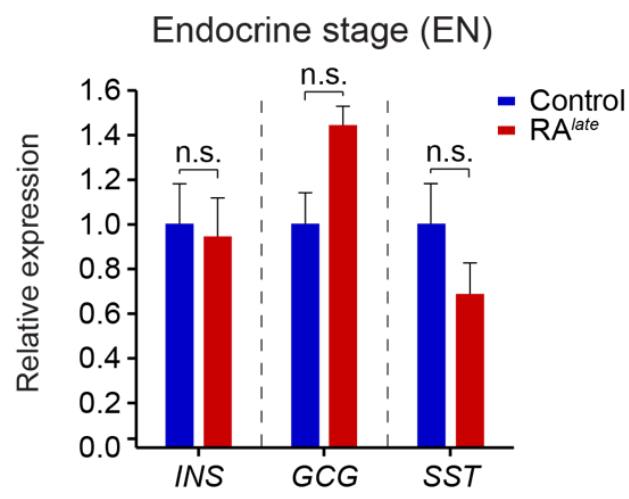

d

Endocrine stage (EN)
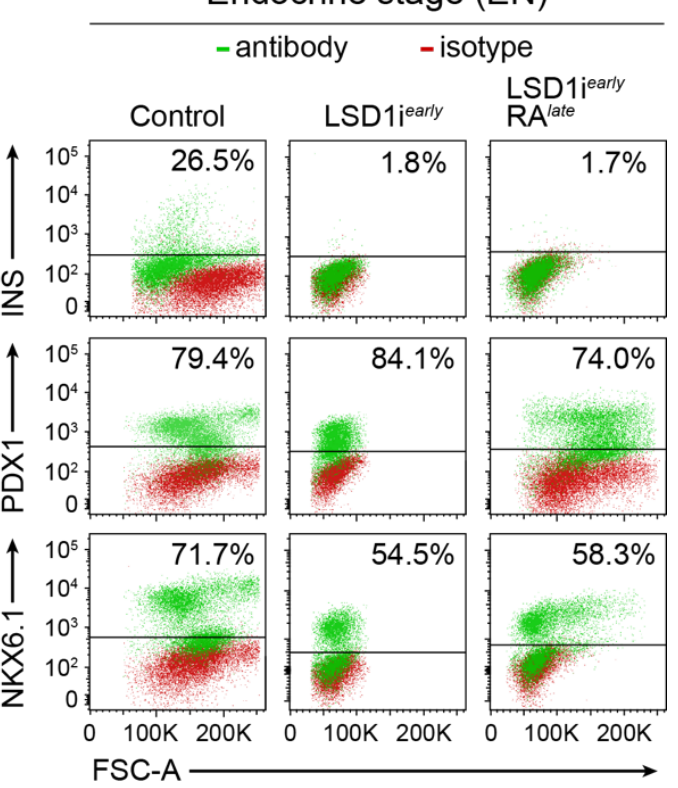

e

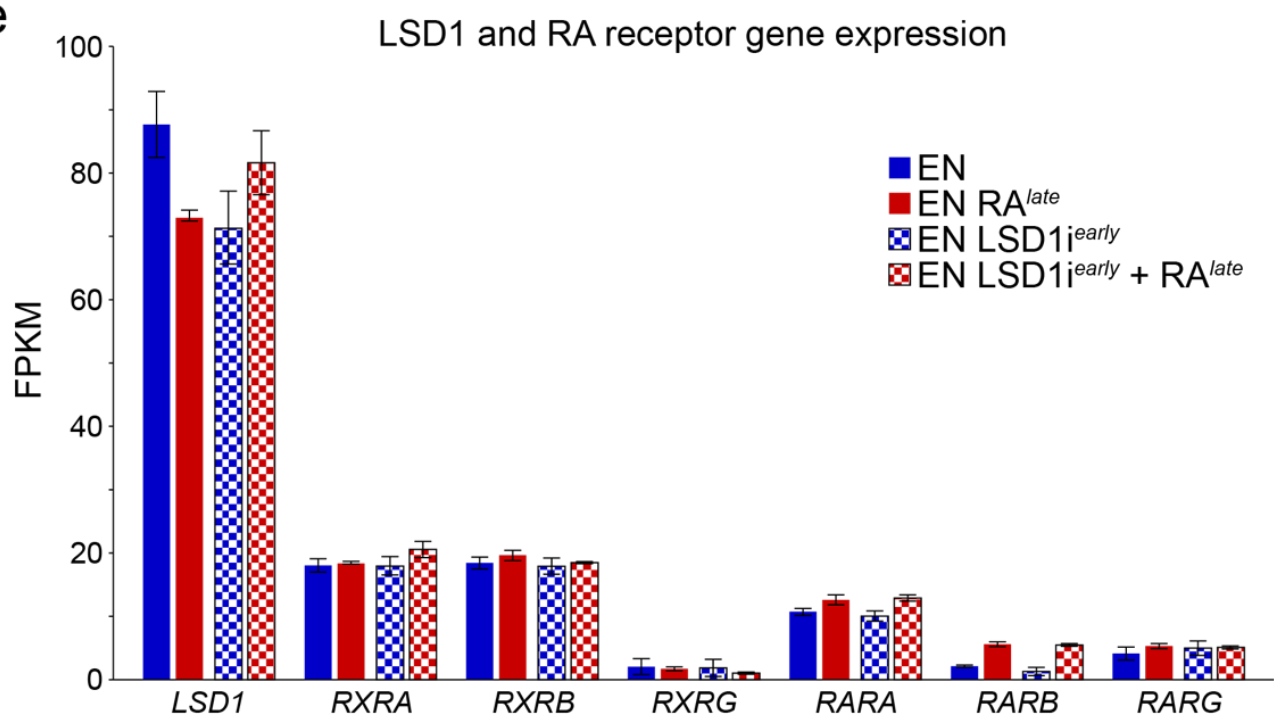


Supplementary Figure 6. Effects of re-introducing retinoic acid during endocrine cell differentiation with and without prior LSD1 inhibition. a, Immunofluorescent staining for PDX1 and NKX6.1 in control endocrine stage cells (EN) compared to EN cells with late retinoic acid (RA) treatment $\left(\mathrm{RA}^{\text {late }}\right)$. Scale bar, $50 \mu \mathrm{m}$. b, qRT-PCR analysis for INS, GCG and SST in control and $\mathrm{RA}^{\text {late }}$ EN cells. Data are shown as mean \pm S.E.M. $(n=2$ biological replicates $)$. n.s. $=p>$ 0.05, Student's t-test. c, Immunofluorescent staining for INS, GCG and SST in control EN cells and EN cells with early LSD1 inhibition (LSD1i $\left.{ }^{\text {early }}\right)$ with and without late RA treatment (LSD1ilate $\left.+\mathrm{RA}^{\text {late }}\right)$. Scale bar, $50 \mu \mathrm{m}$. d, Flow cytometry analysis at EN stage for NKX6.1, PDX1 and INS comparing control EN cells to LSD1i ${ }^{\text {early }}$ EN cells with and without late RA treatment $\left(\mathrm{RA}^{\text {late }}\right)$. Isotype control for each antibody is shown in red and target protein staining in green. Percentage of cells expressing each protein is indicated (representative experiment, $n=2$ ). e, Relative normalised mRNA levels of $L S D 1$ and RA receptor genes at EN stage. Data shown as mean FPKM \pm S.E.M. ( $n=2$ biological replicates). INS, insulin; GCG, glucagon; SST, somatostatin; FSC-A, forward scatter area. 
a Mouse pancreas

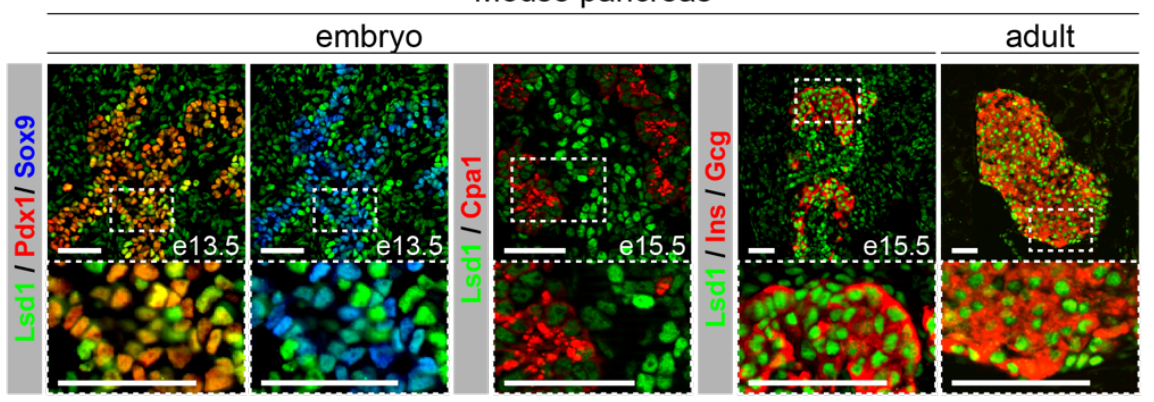

b

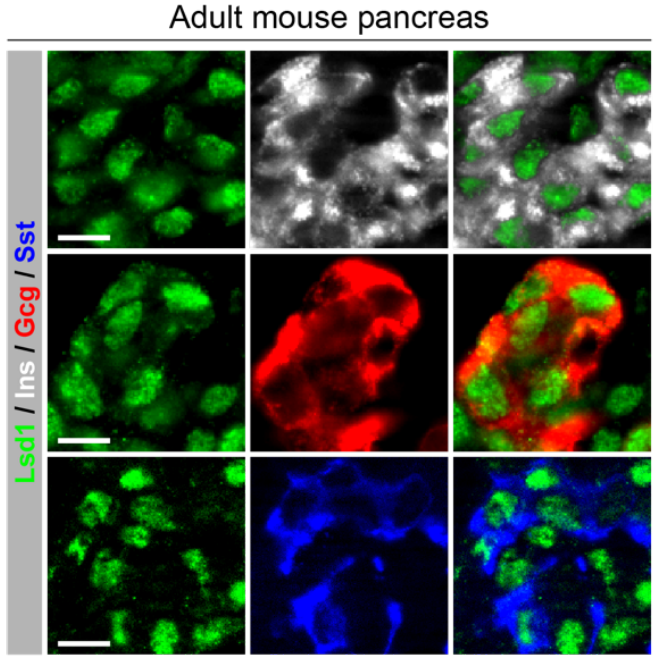

d

Mitotic cells

Apoptotic cells
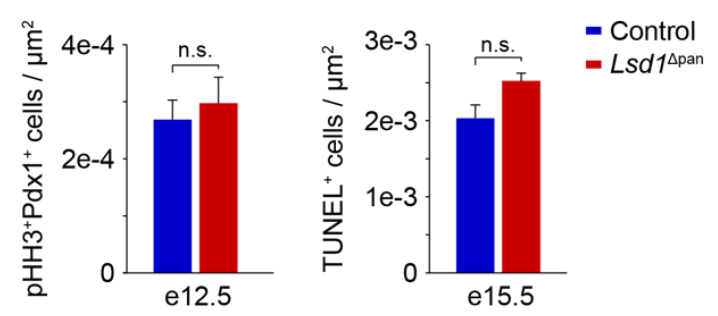

e Hormone ${ }^{+}$cell quantification

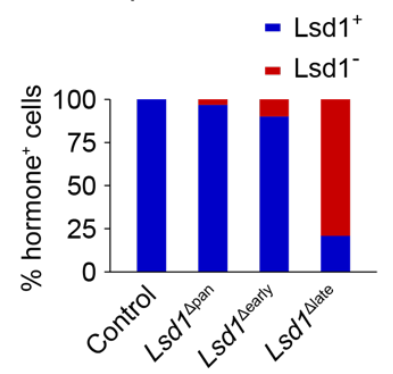

C
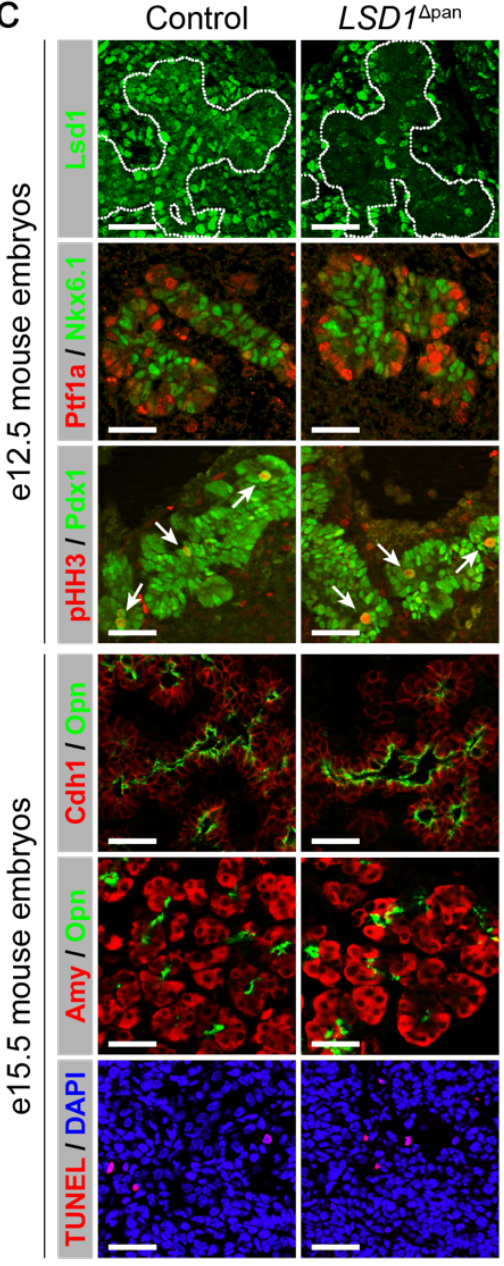


\section{Supplementary Figure 7. Phenotypic characterisation of Lsd1 ${ }^{\Delta \text { pan }}$ mice. a,} Immunofluorescent staining of embryonic (e) and adult mouse pancreas for Lsd1 with the pancreatic progenitor markers Pdx1 and Sox9, the acinar marker carboxypeptidase 1 (Cpa1) or insulin (Ins) and glucagon (Gcg). Boxed areas are shown in higher magnification. Scale bar, 50 $\mu \mathrm{m}$. b, Immunofluorescent staining of adult mouse pancreas for Lsd1 with Ins, Gcg and somatostatin (Sst). Scale bar, $10 \mu \mathrm{m}$. c, Immunofluorescent staining of pancreas from control and Lsd1 ${ }^{\Delta p a n}$ embryos for Lsd1, Ptf1a, Nkx6.1, phospho-histone H3 (pHH3), Pdx1, E-cadherin (Cdh1), osteopontin (Opn), amylase (Amy), and TUNEL. The nuclear counterstain, 4',6-diamidino-2phenylindole $(\mathrm{DAPI})$ is shown together with TUNEL staining. Dashed lines delineate the pancreatic epithelium; arrows point to $\mathrm{pHH} 3$ and $\mathrm{Pdx} 1$ co-positive cells. Scale bar, $50 \mu \mathrm{m}$. d, Quantification of $\mathrm{pHH}^{+}$cells at e12.5 and apoptotic cells $\left(\mathrm{TUNEL}^{+}\right)$at e15.5 relative to pancreatic epithelial area. Data are shown means \pm S.E.M. $(n=3$ per genotype). n.s. $=p>0.05$, Student's t-test. e, Quantification of hormone ${ }^{+}$cells staining positive for Lsd1 in control, $L s d 1^{\Delta \text { pan }}, L s d 1^{\Delta \text { early }}$, and $L s d 1^{\Delta l \text { ate }}$ mice at postnatal day (P) 0. A total of 189-1057 hormone ${ }^{+}$cells (insulin ${ }^{+}$or glucagon ${ }^{+}$) were analysed per genotype and set as $100 \%(n=3$ per genotype). 


\section{Supplementary Tables}

Supplementary Table 1 - Related to Figure 2. LSD1 ChIP-seq peaks at PP1 stage. a, Proximal LSD1 peaks. b, Distal LSD1 peaks.

(supplied as Excel file: Table_S1.xlsx)

\section{Supplementary Table 2 - Related to Figures 2 and 3. Distal LSD1 ChIP-seq peaks at PP1} stage near enhancers. a, LSD1-bound enhancers deactivated from PP1 to PP2. b, LSD1-bound enhancers active at PP1 and PP2. c, LSD1-bound enhancers activated from PP1 to PP2. d, NonG1, G2, G3 LSD1 distal peaks.

(supplied as Excel file: Table_S2.xlsx)

Supplementary Table 3 - Related to Figure 3. Genes regulated by inhibition of LSD1 during PP1 to PP2 transition (LSD1 ${ }^{\text {early }}$ ). a, Up-regulated genes. b, Down-regulated genes.

(supplied as Excel file: Table_S3.xlsx)

Supplementary Table 4 - Related to Figure 3. Genes regulated by inhibition of LSD1 during PP1 to PP2 transition (LSD1i ${ }^{\text {early }}$ ) near enhancers. a, Up-regulated genes near G1 enhancers. b, Up-regulated genes near G2 enhancers. c, Up-regulated genes near G3 enhancers. (supplied as Excel file: Table_S4.xlsx)

Supplementary Table 5 - Related to Figure 3. Gene ontology analysis of genes regulated by inhibition of LSD1 during PP1 to PP2 transition (LSD1i ${ }^{\text {early }}$ ). a, Gene ontology for upregulated genes near G1 enhancers. b, Gene ontology for up-regulated genes near G2. c, Gene ontology for up-regulated genes near G3 enhancers.

(supplied as Excel file: Table_S5.xlsx) 
Supplementary Table 6 - Related to Figure 4. Enriched binding motifs among G1 enhancers compared to $\mathbf{G} 2$ and $\mathbf{G} 3$ enhancers.

(supplied as Excel file: Table_S6.xlsx)

Supplementary Table 7 - Related to Figure 4. Genes regulated by extended treatment with retinoic acid (RA) during PP1 to PP2 transition (RA ${ }^{\text {extended }}$ ). a, Up-regulated genes. b, Downregulated genes.

(supplied as Excel file: Table_S7.xlsx)

Supplementary Table 8 - Related to Figure 5. Gene regulation after late addition of retinoic acid (RA) during PP2 to EN transition (RA ${ }^{\text {late }}$ ). a, Gene expression changes caused by RAlate alone. b, Gene expression changes caused by RA ${ }^{\text {late }}$ following prior LSD1 inhibition during PP2 to EN transition (RAlate + LSD1 iarly $^{\text {) }}$.

(supplied as Excel file: Table_S8.xlsx) 